\title{
CARACTERIZAÇÃO FÍSICO-HÍDRICA DE UM LATOSSOL VERMELHO AMARELO - FASE ARENOSA (HAPLUSTOX)
}

\author{
ANTONIO CADIMA ZEVALLOS
}

Orientador: KLAUS REICHARDT

Tese apresentada à Escola Superior de Agricultura "Luiz de Queiroz", da Universidade de São Paulo, para a obtenção do grau de Doutor em Solos e Nutrição de Plantas.

PIRACICABA

Estado de São Paulo - Brasil

Setembro de 1978 
.$i$.

A memória de meu querido pai,

Pablo Cadima L.

MINHA GRATIDAOO

A minha mãe,

Aos meus irmãos,

A minha esposa Urtinet e aos

meus filhos, Vilma, Pablo e

Sergio, pelo carinho e de-

dicação.

OFEREÇO 
.ii.

\section{AGRADECIMENTOS}

0 autor agradece às seguintes pessoas e Instituições que tornaram possível a realização deste estudo:

- Ao Prof. Dr. Klaus Reichardt, pela orientação, participação, incentivo e apoio na realização deste tra ballho.

- Ao Dr. Paulo Leonel Libardi, pelas sugestões e ines timável colaboração e apoio na realização deste estudo.

- Ao Dr. Virgilio F. do Nascimento Filho, pela atenciosa colaboração nas análises estatísticas.

- Aos Professores e Colegas do Curso de Solos e Nutrisão de Plantas e Energia Nuclear na Agricultura, pela amizade e colaboração.

- A Comissão Executiva do Plano da Lavoura Cacaueira (CEPLAC), meus agradecimentos inesqueciveis pela magnífica oportunidade oferecida.

- A Escola Superior de Agricultura "Luiz de Queir•z" e ao seu Departamento de Solos, Geologia e Fertilizantes, pelos ensinamentos e acolhida. 
.iii.

- Ao Centro de Energia Nuclear na Agricultura (CENA) pelos recursos financeiros obtidos através da Comis são Nacional de Energia Nuclear (CNEN) dentro do "Pro jeto Feijão".

- À Agência Internacional de Energia Atômica (IAEA) pela participação no grupo de Pesquisa Coordenada sobre o Uso de Técnicas Nucleares em Estudos de Regimes de Água.

- Ao Conselho Nacional de Desenvolvimento Cientifico e Tecnológico (CNPq) pela bolsa de estudos concedida.

- E a todos que, de um modo ou de outro, colaboraram para que este trabalho fosse realizado. 
1. RESUMO . . . . . . . . . . . . . . . . . . . . . .

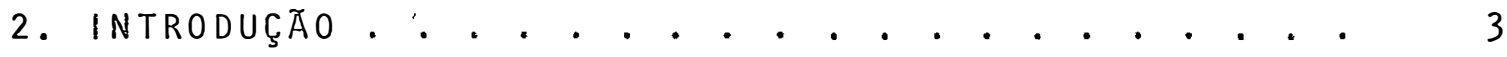

3. ReVisão de literatura. . . . . . . . . . . . . . . 5

3.1. Equações de fluxo. . . . . . . . . . . . . . 5

3.2. Condutividade hidráulica do solo. . . . . 6

3.2.1. Métodos de laboratório... . . . . 6

3.2.2. Métodos de campo.......... . 10

3.3. Variabilidade espacial da condutividade hidráu lica do solo.................... 11

4. MATERIAL E METODOS............................ 14

4.1. Descrição da área... . . . . . . . . . 14

4.2. Medições de campo... . . . . . . . . . . . 15

4.2.1. Parcela experimental . . . . . . . . 15

4.2.2. Condutividade hidráulica em solo saturado................. . . . 15

4.2.3. Tensiômetros . . . . . . . . . . . . . 17

4.2.4. Condutividade hidráulica em solo não saturado . . . . . . . . . . . . . . 19

4.2.5. Curvas de retenção da ägua no solo.. 20

4.3. Aspectos teóricos da metodologia utilizada paa determinação da condutividade hidráulica não saturada... . . . . . . . . . . . . .

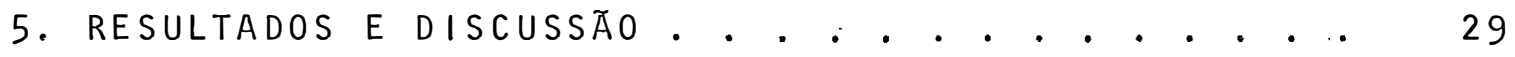

5.1. Anālise física do solo em estudo. . . . . . 29

5.2. Curvas de retenção da água no solo. . . . . . 32

5.3. Condutividade hidráulica de solo saturado. . 32

5.4. Condutividade hidräulica de solo não saturado.. 36 
$\cdot v$.

Pägina

6. CONCLUSÕES.............................. 68

7. SUMMARY . . . . . . . . . . . . . . . . 70

8. Literatura CITAdA. . . . . . . . . . . . . 72 
.vi.

\section{LISTAS DAS FIGURAS}

Figura

Pägina

1 - Disposição das parcelas $(5 \times 5 \mathrm{~m})$ e trincheiras $(2,3 \times 2,3 \times 1,5 \mathrm{~m}) . . . . . . .$.

2 - Diagrama de um tensiômetro instalado no solo $\left(h_{m}=a l t u r a\right.$ do mercūrio; $h_{\text {c }}=$ distância do nível de mercūrio na cuba à c superfície do solo e $h_{z}=$ profundidade). . . . . . . . . .

3 - Parcela experimental com distribuição dos ten siômetros. 0s nümeros 1 a 9 , referem-se às prō fundidades $15,30,45,60,75,90,105,120 \overline{\mathrm{e}}$ $135 \mathrm{~cm}$. . . . . . . . . . . . . . .

4 - Uma das parcelas estudadas mostrando a estrutu ra de madeira, os manômetros numa ūnica cuba de mercürio e as ligações dos tensiômetros. Os nū meros 1 a 9 referem-se às profundidades $15,3 \overline{0}$, $45,60,75,90,105,120$ e $135 \mathrm{~cm}$. . . . ...

5 - Esquema do funil de placa porosa (a) e da câma ra de pressão de Richards (b) . . . . . . . .

6 - Valores de umidade ( $\theta)$ nas diferentes tensões h $(\mathrm{cm})$, nas nove profundidades estudadas: média e intervalo de confiança da média ao nível de $95 \%$ de probabilidade (seis repetições) . . . .

7 - Variação do potencial total da ägua do solo com a profundidade $(z, c m)$ durante a redistribuição da àgua na parcela,l . . . . . . . . . . .

8 - Valores de $\ln K(\theta)$ para $z=15,30,45,60,75$, $90,105,120$ e $135 \mathrm{~cm}$ de profundidade corres-

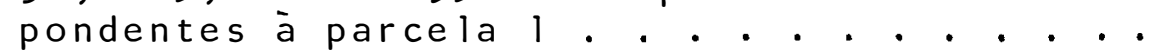

9 - Valores de $\operatorname{lnk}(\theta)$ para $z=15,30,45,60,75$, $90,105,120$ e $135 \mathrm{~cm}$ de profundidade. correspondentes à parcela 2 . . . . . . . . . . 
.vie.

Figura

$\underline{\text { Pägina }}$

10 - Valores de $\operatorname{lnk}(\theta)$ para $z=15,30,45,60,75$, $90,105,120$ e $135 \mathrm{~cm}$ de profundidade correspondentes à parcela 3 . . . . . . . . . . .

11 - Valores médios de $\operatorname{lnk}(\theta)$ para $z=15,30$ e 45 cm de profundidade correspondente às três parcelas. As barras representam desvio padrão da média . . . . . . . . . . . . . . .

12 - Valores médios da $\operatorname{lnk}(\theta)$ para $z=60,75$ e 90 $\mathrm{cm}$ de profundidade correspondente às três parcelas. As barras representam desvio padrão da média . . . . . . . . . . . . . . . .

13 - Valores médios de $\operatorname{lnk}(\theta)$ para $z=105,120$ e $135 \mathrm{~cm}$ de profundidade correspondente às três parcelas. As barras representam desvio padrão da média. . . . . . . . . . . . . . . . . . 
viii.

\section{LISTA DAS TABELAS}

Tabela

Pägina.

1 - Caracterização física do solo Latossolo Verme1 ho Amarelo, Fase Arenosa: $\mathrm{P}_{1}=$ Perfil 1, $\mathrm{P}_{2}=$ Per$\mathrm{fil}^{2}$. . . . . . . . . . . . . . . .

2 - Média $(\bar{x})$, desvio padrão da média (s $\bar{x})$ e inter valo de confiança de média (IC) ao nível de $95 \%$ de probabilidade ( 9 repetições) das caracterís ticas físicas do solo estudado....... .

3 - Média $(\bar{x})$, desvio padrão da média $\left(S_{\bar{x}}\right)$ e inter valo da média (IC) ao nível de $95 \%$ de probabi lidade ( 6 repetições), nas nove profundidades..

4 - Valores da condutividade hidráulica saturada (seis repetições) para cada parcela.....

5 - Valores de umidade volumétrica $\left(\theta, \mathrm{cm}^{3} \cdot \mathrm{cm}^{-3}\right)$ e potencial matricial (h, $\mathrm{cm} \mathrm{H}_{2} \mathrm{O}$ ) para diversos tempos $t$ ( $d i a$ ) e profundidades ( $z, c m$ ) obtidos a partir de leituras de tensiômetros, durante a redistribuição da água na parcela $1 . . . .$.

6 - Valores de umidade volumétrica $\left(\theta, \mathrm{cm}^{3} \cdot \mathrm{cm}^{-3}\right)$ e potencial matricial ( $h, \mathrm{~cm} \mathrm{H}_{2} \mathrm{O}$ ) para diversos tempos $t$ (dia) e profundidades ( $z, c m$ ) obtidos a partir de leituras de tensiômetros,durante a redistribuição da água na parcela 2 . . . . .

7 - Valores de umidade volumétrica $\left(\theta, \mathrm{cm}^{3} \cdot \mathrm{cm}^{-3}\right)$ e potencial matricial ( $h, \mathrm{~cm} \mathrm{H}_{2} \mathrm{O}$ ) para diversos tempos $t$ ( $d i a$ ) e profundidades ( $z, c m$ ) obtidos a partir de leituras de tensiometros,durante a redistribuição da ãgua na parcela 3 . . . . .

8 - Valores de armazenamento $W\left(\mathrm{~cm} \mathrm{H}_{2} \mathrm{O}\right)$ par: diver sos tempos $t$ (dia) e profundidades ( $z, c m$ ) $d u=$ rante a redistribuição da ägua na parcèla 1. . . 
. $i x$

9 - Valores de armazenamento $\mathrm{W}\left(\mathrm{cm} \mathrm{H}_{2} \mathrm{O}\right)$ para diver sos tempos $t$ (dia) e profundidades ( $z, c m) d u=$ rante a redistribuição da āgua na parcela $2 \ldots$

10 - Valores de armazenamento $W\left(\mathrm{~cm} \mathrm{H}_{2} \mathrm{O}\right)$ para diver sos tempos $t$ ( $d i a)$ e profundidades ( $z, c m) d u=$ rante a redistribuição da àgua na parcela 3 .

11 - Valores dos fluxos q, (cm.dia-1) de água no solo nas diversas profundidades $(z, c m)$ e diferen tes tempos $t$ ( $d i a)$ durante a redistribuição dá àgua na parcela l. . . . . . . . . . . . .

12 - Valores de fluxos $q_{1}\left(\mathrm{~cm} \cdot \mathrm{dia}^{-1}\right)$ de āgua no solo nas diversas profundidades $(z ; \mathrm{cm})$ e diferentes tempos $t$ (dia) durante a redistribuição

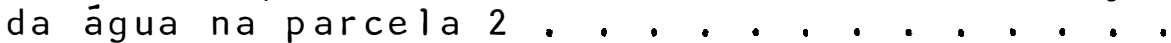

13 - Valores de fluxos q $\left(\mathrm{cm} \cdot \mathrm{dia}^{-1}\right)$ de ägua no solo nas diversas profundidades $(z, c m)$ e diferentes tempos $t$ ( $d i a)$ durante a redistribuição da

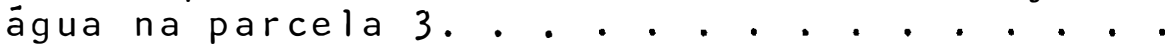

14 - Dados de gradiente de potencial de água no solo $\partial \psi / \partial z\left(\mathrm{~cm} . \mathrm{cm}^{-1}\right)$ nas diversas profundidades $(z, c m)$ e diferentes tempos $t$ (dia) durante a redistribuição da āgua na parcela $1 . . . .$.

15 - Dados de gradiente de potencial de àgua no solo $\partial \psi / \partial z\left(\mathrm{~cm} \cdot \mathrm{cm}^{-1}\right)$ nas diversas profundidades $(z, c m)$ e diferentes tempos $t$ ( $d i a)$ durante a redistribuição da ägua na parcela $2 . . .$. .

16 - Dados de gradiente de potencial de água no solo $\partial \psi / a z\left(\mathrm{~cm} . \mathrm{cm}^{-1}\right)$ nas diversas profundidades $(z, c m)$ e diferentes tempos $t$ ( $d i a)$ durante a redistribuição da ägua na parcela $3 . . . . .$. 
17 - Valores da condutividade hidräulica do solo $\mathrm{K}\left(\mathrm{cm} . \mathrm{di} \mathrm{a}^{-1}\right)$ nas diversas profundidades ( $\mathrm{z}, \mathrm{cm}$ ) e diferentes tempos $t$ (dias) durante a redistribuição da āgua na parcela l. . . . . . . .

18 - Valores da condutividade hidráulica do solo $K\left(\mathrm{~cm} . \mathrm{dia}{ }^{-1}\right)$ nas diversas profundidades ( $\left.z, c m\right)$ e diferentes tempos $t$ (dias) durante a redistribuição da água na parcela 2 . . . . . . .

19 - Valores da condutividade hidráulica do solo $K\left(\mathrm{~cm} . \mathrm{di} a^{-1}\right)$ nas diversas profundidades $(z, \mathrm{~cm})$ e diferentes tempos $t$ (dias) durante a redis tribuição da água na parcela $3 . . .4 . . .$.

20 - Equações representativas da condutividade hidráulica $K\left(\mathrm{~cm} . \mathrm{di} a^{-1}\right)$ versus a umidade $\theta\left(\mathrm{cm}^{3} \cdot \mathrm{cm}^{-3}\right)$ e valores dos coeficientes de determinação $\left(r^{2}\right)$, para diversas profundidades ( $z, c m)$ pertencentes à parcela l. . . . . . . . . . . . . .

21 - Equações representativas da condutividade hidráulica $K\left(\mathrm{~cm} . \mathrm{di}^{-1}\right)$ versus a umidade $\theta\left(\mathrm{cm}^{3} . \mathrm{cm}^{-3}\right)$ e valores dos coeficientes de determinação $\left(r^{2}\right)$, para diversas profundidades ( $z, c m)$ pertencentes à parcela 2. . . . . . . . . . . . .

22 - Equações representativas da condutividade hidráulica $K\left(\mathrm{~cm} \cdot d i a^{-1}\right)$ versus a umidade $\theta\left(\mathrm{cm}^{3} \cdot \mathrm{cm}^{-3}\right)$ e valores dos coeficientes de determinação $\left(r^{2}\right)$, para diversas profundidades $(z, c m)$ pertencen-

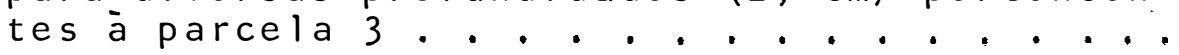

23 - Valores de condutividade hidráulica,para $\theta=0,30 \mathrm{~cm}^{3} \cdot \mathrm{cm}^{-3}$ para as diferentes profundidades nas três parcellas... . . . . . . . . . . . . 
1. RESUMO

Realizou-se um estudo de caracterização de um 0xissol (Haplustox) sob o ponto de vista físico e hídrico em três parcelas experimentais de $5 \mathrm{~m} \times 5 \mathrm{~m}$, localizadas dentro do Campus da Escola Superior de Agricultura "Luiz de Queiroz", Universidade de São Paulo. A determinação dáfunção que rela ciona a condutividade hidräulica ao teor de ägua do solo $K(\theta)$ foi feita pelo método do perfil instantâneo àtravés do proce dimento sugerido por HILLEL et alii (1972) e a modificação in troduzida por CHO et alii (1977).

Procedeu-se tambēm a uma anālise da variabili dade espacial da condutividade hidräulica tanto no sentido ho rizontal como em profundidade, dentro das 3 parcelas experimentais.

os valores de potencial da ägua no solo foram obtidos por meio de tensiômetros instalados nas três parce- 
$j^{2}$.

las às profundidades de $15,30,45,60,75,90,105,120$ e $1.35 \mathrm{~cm}$. Os valores de umidade foram calculados a partir das leiturás dos tensiómetros e de curvas de retenção, elaborados para estas nove profundidades, com amostras de solo com estru tura indeformada. Estas amostras, num total de seis para cada profundidade, eram retiradas de duas trincheiras próximas às parcelas.

Observou-se que a variabilidade espacial da con dutividade hidráulica foi mais acentuada nas camadas superficiais, diminuindo para as camadas mais profundas, motivo pelo qual pode-se dizer que, para profundidades maiores de $75 \mathrm{~cm}$, valores médios podem ser utilizados com relativa segurança, para estudos de fluxo de ägua no solo, e para estabelecimento de balanços hídricos. 


\section{INTRODUÇAO}

A entrada de àgua no solo através de sua super fície recebe o nome de infiltração e se relaciona a diversos problemas agronômicos como, por exemplo, conservação de água no perfil de solo, poluição da água subterrânea e erosão do solo, os. quais têm sido objeto de pesquisas nas mais variadas regiões do globo.

A quantificação do movimento de àgua no intẹ rior do solo pode ser obtida por uma equação denominada equação de Darcy. De modo geral, o maior problema na utilização desta equação tem sido a determinação da condutividade hidráu lica do solo que é uma função de sua umidade. A condutividade hidrāulica é um parâmetro que descreve a propriedade do so lo em transmitir àgua. Para a determinação desta função, os primeiros métodos desenvolvidos foram de laboratörio utilizan do amostras de solo com estrutura deformada e posteriormente esses métodos foram adaptados para amostras de solo com estru 
tura indeformada. Na prática, porēm, observa-se que toda amos tragem de solo causa alguma perturbação em seu arranjo poroso. E evidente, portanto, que a melhor maneira è executar as medições no prōprio campo. 0 método mais empregado atualmente para a determinação da condutividade hidráulica como uma função da umidade, sob condições de campo, é o do perfil instantâneo.

Este trabalho foi efetuado em um $0 \times$ issol, loca lizado no Município de Piracicaba, com o objetivo de caracte rizá-lo sob o ponto de vista físico e hídrico, especialmente quanto à condutividade hidrāulica pelo método do perfil instantâneo. Para isto empregou-se o procedimento sugerido por HILLEL et alii (1972) com a modificação introduzida por CHO et alii (1977). Um segundo objetivo foi estudar a variabilidade espacial de suas propriedades físicas, tanto no sentido horizontal como no sentido vertical. 0 problema da variabil dade espacial é assunto de fronteira na ciência do solo, como pode ser verificado nas discussões de congressos recentes e na literatura mundiàl publicada nos ültimos anos. Informações detalhadas sobre a variabilidade espacial de propriedades hídricas de um solo, são essenciais para a obtenção de valores médios representativos de grandes áreas agrícolas, que possam ser utilizados com segurança na estimativa e previsão da dinâ mi ca da àgua no solo. 


\section{REVISAOO DE LITERATURA}

\subsection{Equações de Fluxo}

Efetuando experiências de infiltração em colunas de areia saturada de água, DARCY (1856), utilizando um per meâmetro de carga constante, obteve uma equação que estabelece que o fluxo ou a quantidade de água transmitida por unidade de tempo e de área é proporcional ao gradiente hidráulico, sendo a constante de proporcionalidade denominada condutivida de hidráulica saturada.

De maneira semelhante, BUCKINGHAM (1907) apresentou uma equação de fluxo para solo não-saturado definindo os conceitos de potencial matricial e condutividade hidráulica não-saturada. Esta equação tem sido denominada por SWARTZEN DRUBER (1969) de equaqão de Buckingham-Darey.

Combinando a equação de Darcy com a equação da continuidade, SLICHTER (1898) obteve a equação diferencial ge 
ral que rege o movimento de ägua em meio poroso saturado. Por outro lado, RICHARDS (1931) combinou a equação de Buckingham- Darcy com a da continuidade obtendo a equação diferencial que recebe seu nome e que descreve o movimento da água em solo não-saturado.

\subsection{Condutividade Hidrāulica do Solo}

Como acabamos de ver, a condutividade hidráuli ca é simplesmente um coeficiente de proporcionalidade entre o fluxo e o gradiente hidráulico e representa uma propriedade do solo em transmitir água. :

De modo geral, os métodos de determinação da condutividade hidráulica podem ser subdivididos em duas categorias: métodos de laboratório e métodos de campo.

\subsubsection{Métodos de laboratório}

\footnotetext{
Nos mētodos de laboratōrio, utilizam-se amos tras de solo homogeneamente acondicionadas em colunas, ou amos tras de solo com estrutura indeformáda.
}

Um dos primeiros trabalhos a apresentar um mé- 
todo de determinação da condutividade hidráulica foi o de RICHARDS (1931). Neste trabalho o autor utilizou uma pequena coluna de solo entre duas placas porosas de cerâmica e manteve um gradiente de potencial constante entre ambas,através de colunas de água. O valor da condutividade hidráulica era obti do pela equação de Darcy ou pela equação de Buckingham-Darcy, sob condições de equilíbrio dinâmico.

Através da utilização de condições de contorno adequadas, RICHARDS e WEEKS (1953), a partir da integração da equação de Richards, apresentaram um método de determinação da condutividade hidráulica do solo como função de sua umidade, o qual é conhecido como método do perfil instantâneo.

Pesquisando a infiltração horizontal da ãgua em colunas de solo homogêneo, BRUCE e KLUTE (1956) determinaram uma equação, na qual, conhecendo-se o perfil de umidade em um dado instante, calcula-se a difusividade da água no solo, para qualquer umidade. Comó a condutividade hidráulica é igual à difusividade da água no solo multiplicada pela capaci dade de água (KLUTE, 1973, que è a tangente à curva umidade versus potencial matricial), a partir da curva de retenção de água no solo e da curva da difusividade versus umidade, pode-se obter a curva condutividade hidráulica versus umidade do solo. Muitos pesquisadores utilizaram esta metodologia pa ra calcular a condutividade hidráulica do solo,podendo-se men 
.8 .

cionar REICHARDT et alii (1972) que a empregaram em solos que ocorrem em clima temperado e LIBARDI (1974) em solos que se desenvolvem em clima tropical.

VACHAUD (1967) procurando demonstrar a validade da lei de Darcy, com a utilização de dados de fluxo e de gradiente de potencial, delineou um experimento de infiltra ção horizontal determinando a umidade do solo a vārias distân cias em função do tempo. Empregando esses dados juntamente com os-da curva de retenção, desenhou o potencial matricial em função da distância e do tempo e obteve os gradientes de potencial para tempos determinados. Utilizando os valores de gradiente conseguidos desse modo e os do fluxo calculados diretamente numa bureta de Mariotte, desenhou a figura fluxo ver sus gradiente para diferentes tempos e umidades, obtendo uma relação linear, confirmando-se assim a validade da lei de Dar cy. 0s valores dos coeficientes angulares de cada linha obti da era igual à condutividade hidráulica para a umidade corres pondente.

Em nosso meio, REICHARDT et alii (1975) propõem um método que se baseia na técnica do "scaling" no qual o valor da condutividade hidráulica é facilmente obtido atra vés de uma equação generalizada apresentada por estes autores. Mais recentemente, CAVALCANTE et alii (1978) empregou o procedimento de HILLEL et alii (1972) para o cál.culo da condutividade hidráulica em função da umidade do solo sob condições 
de laboratọrio, estimando a umidade do solo pela técnica de atenuação da radiação gama e o potencial matricial a partir da curva característica da àgua do solo.

A partir de amostras de solo com estrutura não deformada, ALEMI et alii (1976) propõem um método que consiste em centrifugar a amostra de solo obtendo uma equação analí tica para a umidade em função da distância e do tempo, a par tir da qual a condutividade pode ser estimada. A redistribui ção de água dentro da amostra de solo úmido, após a centrifugação é medida gravimetricamente e analisada em termos de equa ção de fluxo.

Métodos que também podem ser considerados como métodos de laboratório são aqueles em que a condutividade hi dráulica é calculada a partir de outras propriedades do meio poroso de mais fácil determinação. Assim, pesquisadores como CHILDS e COLLIS-GEORGE (1950), MARSHALL (1958) e MILLINGTON e QUIRK (1959, 1960 e 1961) obtiveram equações matemáticas pạ ra calcular a condutividade hidráulica não saturada, partindo da distribuição do tamanho de poros do solo. Posteriormente, outros investigadores tentaram utilizar estas equações com dạ dos experimentais, sendo que NIELSEN et alii (1960) , efetuaram comparações dos métodos de CHILDS e COLLIS-GEORGE (1950) e MARSHALL (1958), com o método do perfil instantâneo em quatro solos, mostrando que os resultados dos primeiros foram me Ihores do que os do segundo. 


\subsubsection{Métodos de Campo}

A maioria dos métodos de campo são adaptações dos métodos de laboratório e normalmente se diferem entre si por utilizarem diferentes técnicas para determinação de parâmetros como umidade do solo e potencial matricial.

Assim, RICHARDS et alii (1956) adaptaram o método de RICHARDS e WEEKS (1953) para condições de campo,medin do a umidade gravimetricamente e o potencial matricial por meio de tensiômetros com manômetro de mercūrio. OGATA e RICHARDS (1957) utilizaram o mesmo procedimento de RICHARDS et alii (1956) porèm deixaram que o perfil sofresse apenas o proces: so de drenagem, cobrindo a superfície do solo com plästico pạ ra obter nesta posição um fluxo sempre nulo.

NIELSEN et alii (1962) empregaram o mesmo procedimento de OGATA e RICHARDS (1957), com a diferença que uti lizaram a sonda de neutrons para medições de umidade. Este procedimento é o que tem sido mais empregado em condições de campo devido à facilidade que a técnica da sonda de neutrons oferece, tendo ainda a vantagem de ser pouco destrutiva. Neste sentido podem-se citar os trabalhos de ROSE et alii (1965), HILLEL et alii (1972), CHO et alii (1976), VACHAUD et alii (197?), REICHARDT e LIBARDI (1974), GROHMANN et alii (1976), SAUNDERS et alii (1978), etc. 
VACHAUD et alii (1977) estudando dois solos tí picos da Repüblica de Senegal, obtiveram a condutividade hidrāulica não-saturada por dois métodos denominados de drena- gem interna e do balanço natural, que analisados em profundidade não diferem do método do perfil instantâneo de RICHARDS e WEEKS (1953) e RICHARDS et alii (1956).

Ultimamente SIMMONS et alii (1978), num relatō rio sobre "scaling" das propriedades hidráulicas do solo em condições de campo, apresentaram um método melhorado de estimativa da condutividade hidráulica não saturada através da utilização de fatores de "scaling".

3.3. Variabilidade Espacial da Condutividade Hidrāulica do Solo

Tendo em vista que a relação entre o conteūdo de água do solo e a condutividade hidráulica se trata de uma função exponencial, deduz-se que uma pequena variação do conteüdo de ăgua do solo implica numa grande variação da conduti vidade hidráulica. Buscando vencer esta dificuldade NIELSEN et alii (1973) expressam a condutividade hidráulica em função da porcentagem de saţuração.

Referindo-se à variabilidade espacial da condu 
tividade hidráulica, esta tem despertado grande interesse quando observada em medições de campo. Assim BAKER et alii (1974) asseguram que esta variabilidade é devida a problemas técnicos de medida e às características do próprio perfil do so10. Nos estudos da variabilidade espacial em três parcelas de $5 \times 5$ m de.um Alfisol, REICHARDT et alii (1976) obtiveram grande variabilidade em torno do valor médio da condutividade hidráulica verificando erros de \pm 100 vezes, tornando difícil a determinação do fluxo de água do solo em condições de campo.

Calculando-se a condutividade hidráulica pela equação de Darcy, dividindo-se o fluxo de água pelo gradiente de potencial, observa-se que os motivos principais do aparecimento de erros neste parâmetro devem-se às medidas de umi dade e potencial matricial. Aplicando a técnica de erro multivariável, FLUHLER et alii (1976) deduzem por meio de equações o erro da função através dos erros das variáveis. CLIFFOED (1973) determinou que os erros na variação do conteúdo de água são significativos quando a drenagem é lenta, devido possivelmente a não saturação do solo, e que os erros que provêm da leitura de tensiômetros são significativos quan do o valor do gradiente de potencial era inferior a 0,3 mBar. $\mathrm{cm}^{-1}$. Concluíram também que èm condições próximas à saturação o erro apresentado pela condutividade hidráulica varia de 20 a $30 \%$. Quando o valor é pequeno os erros relativos podem ser superiores a $100 \%$. 
.13.

Pesquisando as propriedades hidrodinâmicas dos principais solos de Morandaba em Madagascar, MARINI et aZii (1977) verificaram que nos solos com mais de $80 \%$ de areia, uma variação de $3 \%$ no conteūdo de àgua do solo condicionava uma variação de 4,5 vezes no valor da condutividade hidräulica, quando o fluxo de ägua se tornava lento, e em solos arenosos com menos de $80 \%$ de areia, 5,5 vezes. 
.14.

4. MATERIAL E METODOS

4.1. Descrição da Ārea

o presente experimento foi realizado na Fazenda Sertãozinho, do Departamento de Solos, Geologia e Fertilizantes. O local da instalação era próximo do Posto Meteoroló gico do Departamento de Física e Meteorologia da ESALQ, cujas coordenadas geogräficas são $22^{\circ} 42^{\prime} 39^{\prime \prime}$ de latitude sul e $47^{\circ} 38^{\prime} 00^{\prime \prime}$ de longitude 0este, altitude $580 \mathrm{~m}$.

o clima da região se caracteriza, segundo a classificação de Wilhelm Köeppen, como sub-tropical com inver no seco (CWA) e, de acordo com a classificação de Thornthwaite, como de tipo úmido, com pequena deficiência de água, megatérmico, com pequena oscilação térmica no ano ( $\left.C_{2} r A^{\prime} a^{\prime}\right)$. Apresen ta uma precipitação pluviométrica média anual de $1247 \mathrm{~mm}$, com $20,8^{\circ} \mathrm{C}$ de temperatura e $69 \%$ de umidade relativa. 
Segundo informações verbais (*) o solo da área selecionada é classificado como um Latossol Vermelho Amare10 - Fase Arenosa (Haplustox).

4.2. Medições de Camipo

4.2.1. Parcela Experimental

0 experimento se constiuiu de 3 parcelas experimentais niveladas e com dimensões de $5 \times 5 \mathrm{~m}$ cada uma, sepa radas entre si de $8,3 \mathrm{~m}$ (Figura 1). Em volta de cada parcela foi colocado um dique de terra formando uma bacia de $30 \mathrm{~cm}$ de profundidade, a fim de proceder sua inundação.

\subsubsection{Condutividade Hidráulica em Sollo Saturado}

Iniciou-se a infiltração colocando ägua nas par celas por meio de uma mangueira ligada a um caminhão pipa. A parcela experimental foi inundada durante duas horas consecutivas mantendo-se na superfície uma lâmina de aproximadamente $15 \mathrm{~cm}$. Para saber se atingiu uma condição de equilíbrio dinạa

(*) Professor J.L.I. DEMATTE, Departamento de Solos, Geologia e Fertilizantes - ESALQ. 


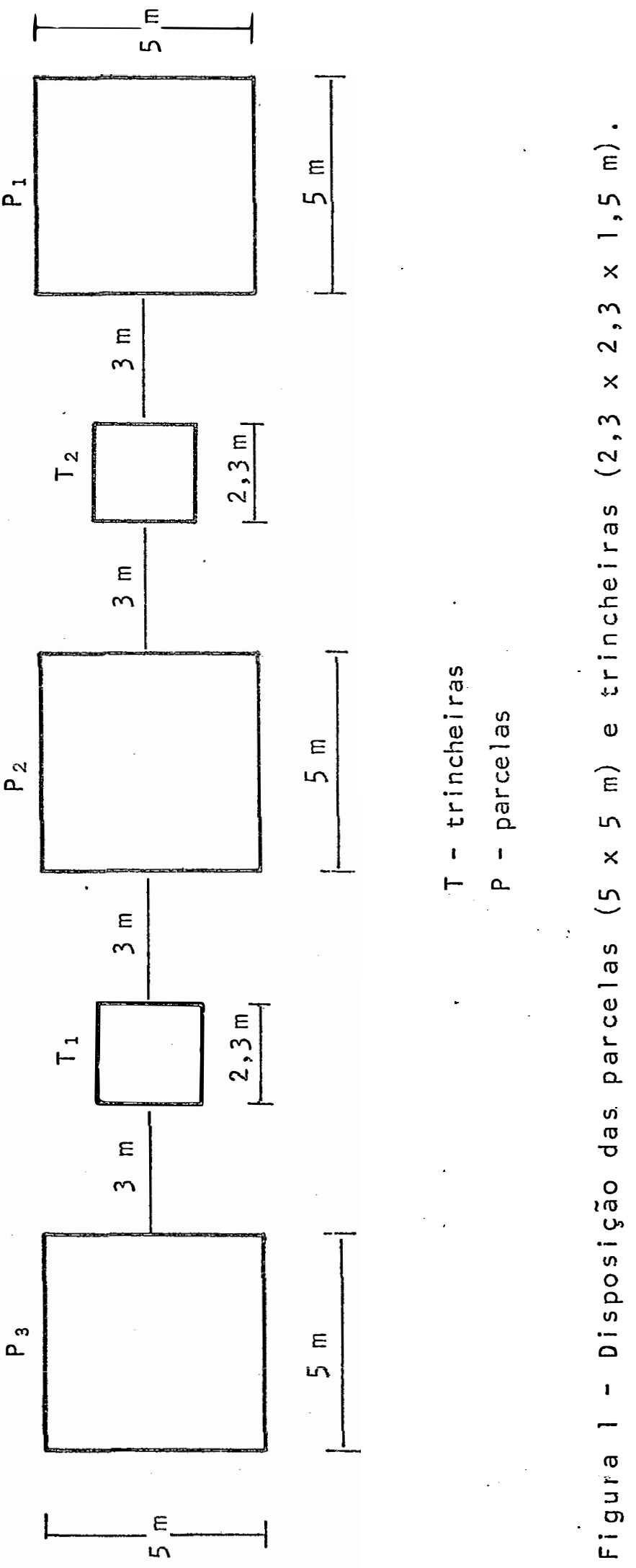


mico, observaram-se as alturas das colunas de mercūrio nos ten siômetros, pois, quando estas permanecem constantes, é indica ção de que a umidade não está mais variando, havendo por conseguinte, fluxo constante.

Uma vez verificada a condição de infiltração em equilíbrio dinâmico, instalaram-se cilindros de plástico PVC de $30 \mathrm{~cm}$ de diâmetro e $40 \mathrm{~cm}$ de altura em dois locais pa-. ra cada parcela. Com a ajuda de uma escala graduada foi efetuada a medição da altura da lâmina de água infilttrada para um determinado intervalo de tempo, calculando-se assim a condutividade hidráulica saturada.

\subsubsection{Tensiōmetros}

Na Figura 2, apresenta-se o diagrama de um ten siômetro que consiste de um tubo plástico PVC de $1 / 2$ polegada de diâmetro, de comprimento variável de acordo com a profundi dade na qual se deseja obter o valor do potencial matricial, tendo numa das extremidades uma cápsula porosa e na outra uma rolha de borracha ajustada. Um tubo de "nylon" de $2 \mathrm{~mm}$ de diâa metro é conectado numa das extremidades ao tubo PVC e na outra a um tubo de vidro de $2,5 \mathrm{~mm}$ de diâmetro e $80 \mathrm{~cm}$ de comprimento o qual é imerso numa cuba de mercürio. 


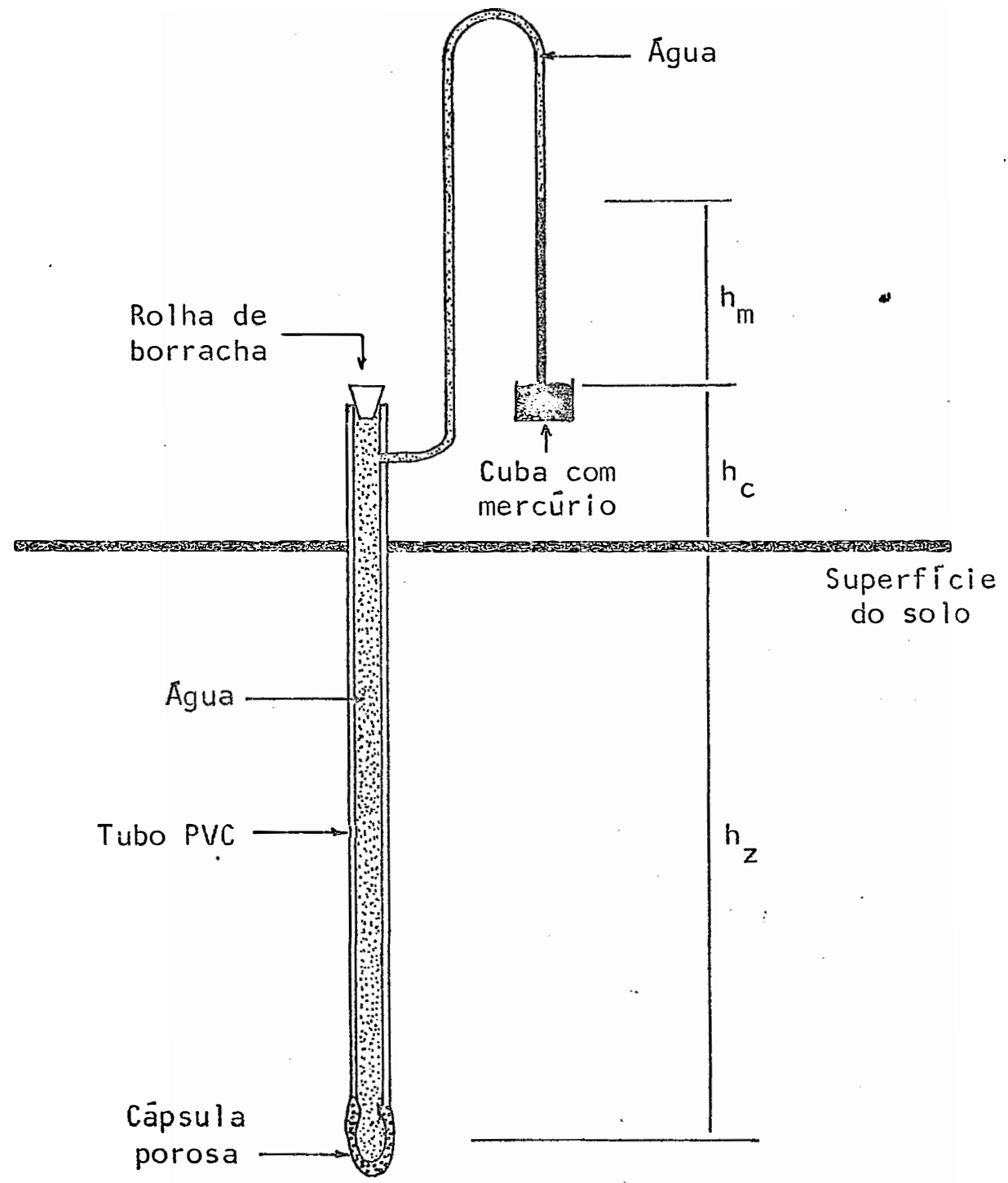

Figura 2 - Diagrama de um tensiômetro instalado no. solo $\left(h_{m}=a l t u r a\right.$ do mercürio; $h_{c}=$ distância do nível de mercürio na cuba à superfície do solo e $h_{z}=$ profundidade). 
cūrio $\left(h_{m}\right)$, da distância da superfície do solo ao nível de mercūrio na cuba $\left(h_{c}\right)$ e da profundidade de instalação da căpsü la porosa $\left(h_{z}\right)$, foram empregados nas fórmulas.

$$
\psi_{m}=-12,6 h_{m}+h_{c}+h_{z} . . . . . . .
$$

e

$$
\psi=-12,6 h_{m}+h_{c} . \ldots . . . . . . .
$$

para o cálculo do potencial matricial $\left(\psi_{m}\right)$ e do potencial total $(\psi)$, respectivamente.

Para a instalação dos tensiômetros foram abertos orifícios no solo com a ajuda de um trado helicoidal de diâmetro igual ao dos tensiômetros. Depois adicionou-se um pouco de água para facilitar a entrada dos tensiómetros nos orifícios, até se obter um contacto perfeito entre o solo e a cápsula porosa, na profundidade desejada.

4.2.4. Condutividade hidrāulica em Solo não Saturado

A fim de se obter dados de condutividade hidrāulica não saturada, foram instalados 27 tensiômetros de ma nômetro de mercúrio sendo 9 em cada parcela. e cobriram-se as parcelas com plástico de $40 \mathrm{~m}^{2}$ após a determinação da con- 
dutividade hidráulica saturada. Devido a que o solo è arenoso com alta taxa de infiltração, as leituras após a cobertura da superfície do solo com plástico, nas duas primeiras horas foram feitas de 15 em 15 minutos, em seguida de hora em hora, depois a intervalos de dias e ultimamente semanas.

Os nove tensiómetros instalados em cada parcela correspondem às profundidades $15,30,45,60,75,90,105$, 120 e $135 \mathrm{~cm}$. Neste experimento os nove tubos de vidro correspondentes a cada tensiómetro foram imersos numa ünica cuba de mercúrio, fixa a uma estrutura de madeira instalada próxima à margem da parcela experimental. Este processo, facilitou as leituras das colunas de mercūrio que eram feitas com auxílio de uma régua.

Na F́ igura 3 observa-se a distribuição dos tensiómetros nas 9 profundidades e na Figura 4 a estrutura de ma deira com os manómetros de mercūrio e as ligações com os respectivos tensiômetros às nove profundidades.

4.2.5. Curvas de Retenção da Agua no Solo

As curvas de retenção da água no solo foram fe tas por secamento em amostras de solo com estrutura indeforma da. Utilizou-se funil de placa porosa para tensões no inter- 

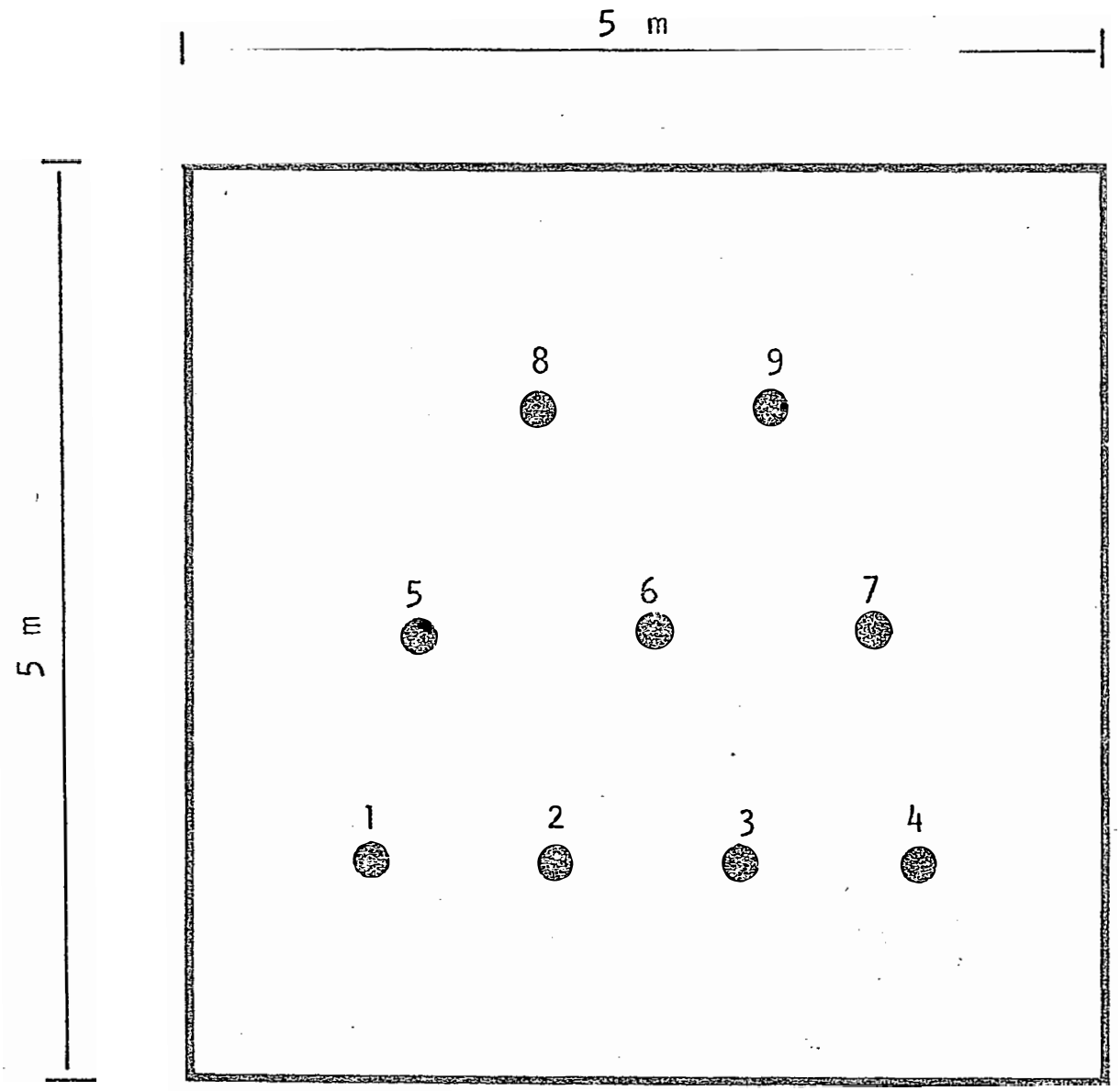

Figura 3 - Parcela experimental com distribuição dos tensiômetros. Os nümeros 1 a 9 , referem-se às profundidades $15,30,45,60,75,90,105,120$ e $135 \mathrm{~cm}$. 


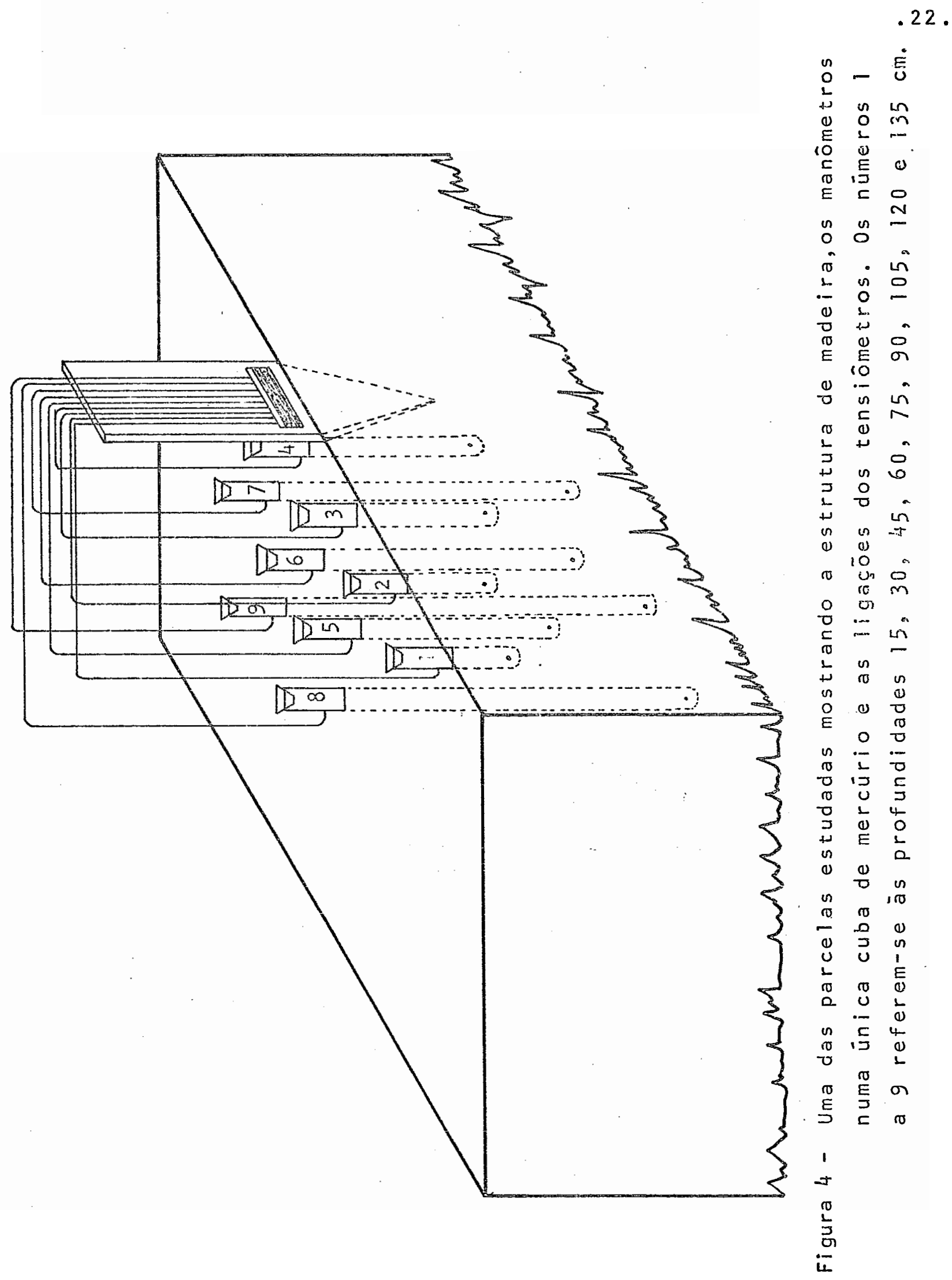


valo de $0-200 \mathrm{~cm} \mathrm{H} \mathrm{H}_{2}$, e "panela de pressão" para as tensões de 300,500 e $800 \mathrm{~cm} \mathrm{H}{ }_{2}$. Na Figura 5 observam-se os esquemas do funil de placa porosa e da câmara de pressão de Richards (ou "panela de pressão").

As amostras de solo foram obtidas em duas trin cheiras feitas próximas das parcelas (Ver Figura 1). A retirada das amostras era feita por meio de um pequeno cilindro de PVC de $60,7 \mathrm{~cm}^{3}$, com uma extremidade cortante através dá qual a amostra era facilmente retirada por simples pressão,es tando o perfil previamente umedecido. Obtiveram-se nove curvas características correspondentes às nove profundidades de instalação dos tensiômetros e retiraram-se seis amostras de cada profundidade. As amostras foram saturadas durante 48 ho ras e em seguida submetidas às respectivas tensões.

Por este mesmo procedimento de amostragem, determinaram-se os valores de densidade global para cada profun didade do perfil.

4.3. Aspectos Teōricos da Metodologia utilizada para deter minação da Condutividade Hidrāulica não saturada

No presente experimento, a determinação da con dụtividade hidráulica não saturada foi feita pelo método do 
(a)

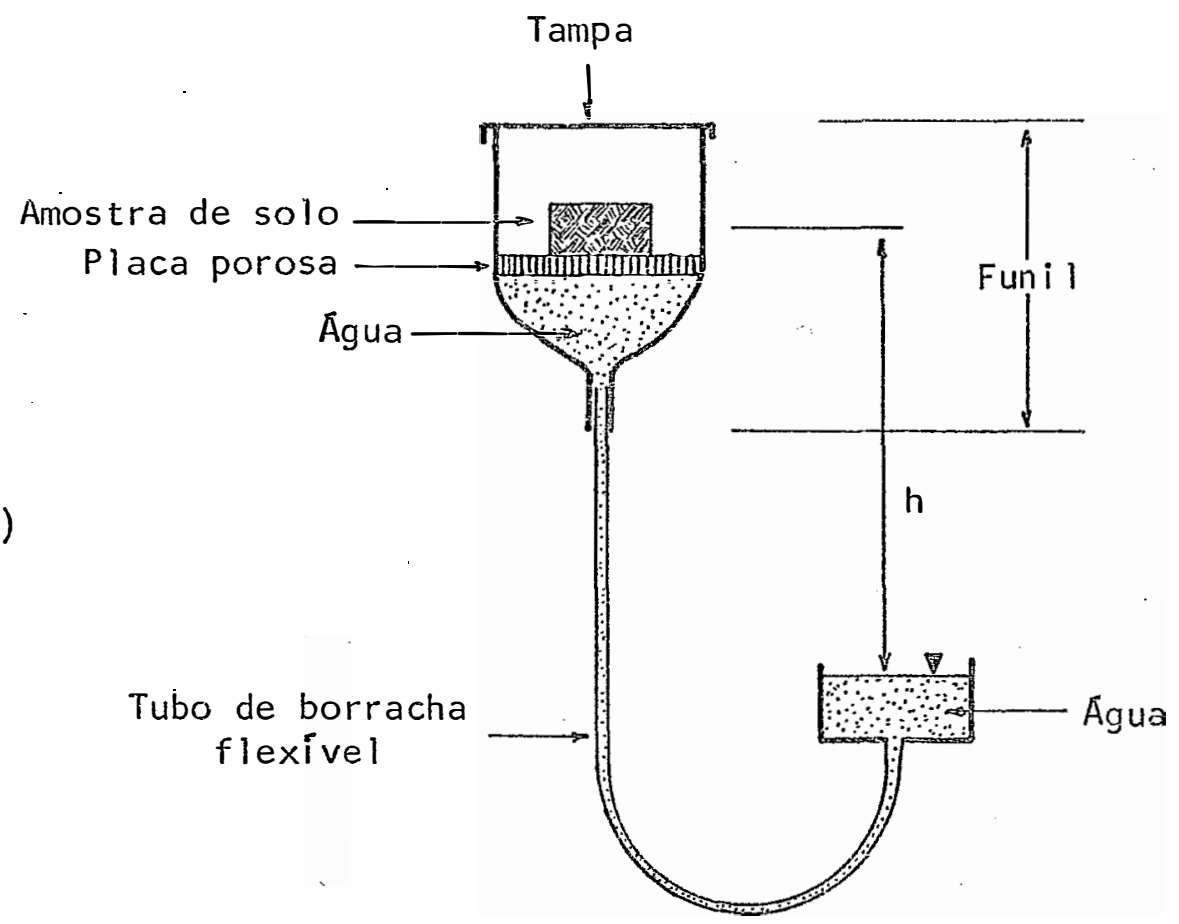

(b)

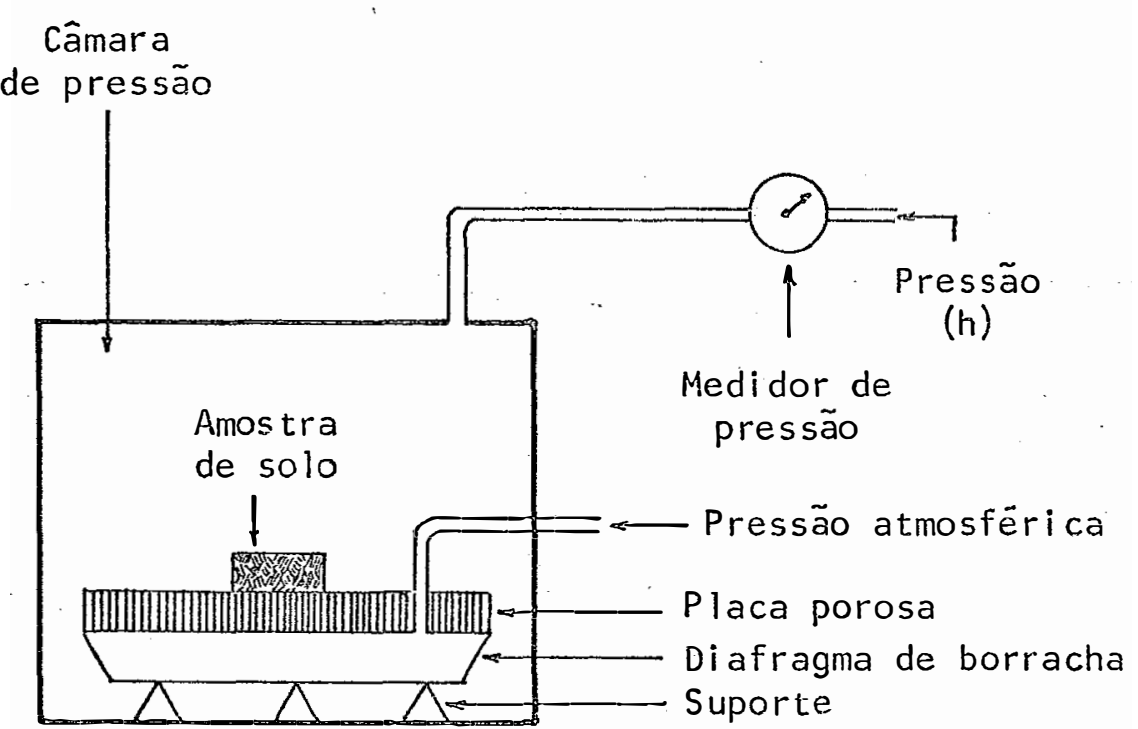

Figura 5 - Esquema do funil de placa porosa (a) e da câmara de pressao de Richards (b). 
perfiz instantâneo através do procedimento utilizado por. HILLEL et alii (1972) com a modificação introduzida por CHO et.alii (1977).

Como jā vimos, a equação de Buckingham-Darcy nos fornece o fluxo de àgua em solo não-saturado, o qual é igual ao produto da condutividade hidräulica não-saturada pelo gradiente de potencial. Matematicamente, pode ser escrita:

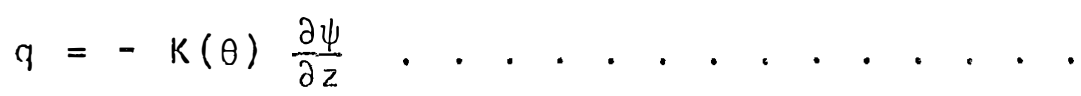

onde:

$$
\begin{aligned}
q= & f l u x o \text { de āgua }\left(L \cdot T^{-1}\right) . \\
K(\theta)= & \text { condutividade hidrāulica não-saturada do } \\
& \text { solo }\left(L T^{-1}\right), \text { que é função de seu conteüdo } \\
& \text { de ägua } \theta\left(L^{3} \cdot L^{-3}\right) . \\
\psi= & \text { potencial total da ägua no solo }(L) . \\
z= & \text { coordenada vertical de posição }(L) .
\end{aligned}
$$

Combinando a equação de Buckingham-Darcy com a equação da continuidade,

$$
\frac{\partial \theta}{\partial t}=-\frac{\partial q}{\partial z}, \cdot . \cdot . \cdot \cdot \cdot \cdot \cdot \cdot \cdot \cdot \cdot \cdot \cdot
$$

obtèm-se a equą̃̃o de Richards, 


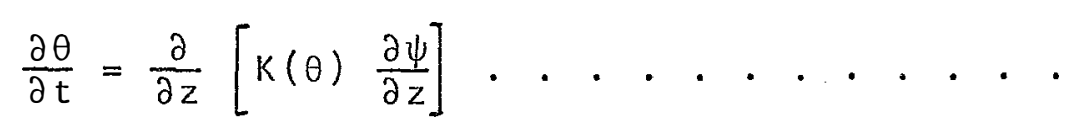

que è a equação diferencial geral que descreve o movimento da ägua em solos não-saturados.

Após a saturação do solo e a cobertura de sua superfície complástico (Ver ítens 4.2.2. e 4.2.4.), a ägua no seu interior se redistribui pelo processo de drenagem interna e, nestas condições, integrando a equação (5) com rela: ção a $z$ da superfície do solo $(z=0)$ a uma profundidade qual quer $(z=L)$, obtém-se:

$$
\int_{0}^{L} \frac{\partial \theta}{\partial t} d z=\left[K(\theta) \frac{\partial \psi}{\partial z}\right]_{0}^{L} \cdot \ldots . . . . .
$$

ou

$$
\int_{0}^{L} \frac{\partial \theta}{\partial t} d z=\left[\begin{array}{ll}
K(\theta) & \frac{\partial \psi}{\partial z}
\end{array}\right]_{L}-\left[K(\theta) \frac{\partial \psi}{\partial z}\right]_{0} \ldots .
$$

Devido a que a superfície do solo foi revestida complástico, em $z=0 \circ f l u x o$ é nulo e a equação (7) fica:

$$
\int_{0}^{L} \frac{\partial \theta}{\partial t} d z=\left[K(\theta) \frac{\partial \psi}{\partial z}\right]_{L}=[K(\theta)]_{L} \cdot\left(\frac{\partial \psi}{\partial z}\right)_{L}=q_{L} \cdots
$$


Explicitando $K(\theta)$ da equação (8), obtemos:

$$
[K(\theta)]_{L}=\frac{\int_{0}^{L} \frac{\partial \theta}{\partial t} \cdot d z}{\left(\frac{\partial \psi}{\partial z}\right)_{L}} \cdot . \cdot . \cdot \cdot
$$

onde:

$$
\begin{aligned}
& \int_{0}^{L} \frac{\partial \theta}{\partial t} d z=q_{L}=f l u \times 0 \text { em } z=L . \\
& \left(\frac{\partial \psi}{\partial z}\right)_{L}=\text { gradiente de potencial em } z=L . \\
& {[K(\theta)]_{L}=\text { condutividade hidrāulica em } z=L .}
\end{aligned}
$$

No procedimento de HILLEL et alii (1972) para o cälculo de $K(\theta)$, a integral da equação (9) ē aproximada por uma somatória da seguinte manei ra:

$$
q_{L}=\int_{0}^{L} \frac{\partial \theta}{\partial t} d z \simeq \sum_{i=1}^{n} \frac{\partial \bar{\theta}_{i}}{\partial t} \cdot \Delta z \cdot . . . \cdot .
$$

Nesta equação $(10), \bar{\theta}_{i}\left(=\bar{\theta}_{1}, \bar{\theta}_{2}, \bar{\theta}_{3}, \ldots, \bar{\theta}_{n}\right)$ são as umidades mëdias das camadas de solo $\Delta z$, o índice $i(=.1,2,3, \ldots, n)$ representa as camadas a partir da superfície e $L=n \Delta z$. Assim, 
medindo-sè $\theta$ em função de $z$ e $t, q_{L}$ é facilmente determinado, calculando-se $\partial \theta / \partial t$ a partir de gráficos de $\theta$ versus $t$ para ca da camada. De maneira idêntica, os valeres de $\partial \psi / \partial z$ são facilmente determinados medindorse $\psi$ em função de $z$ e $t$.

A modificação introduzida por CHO et alii (1977) consistiu àpenas em verificar que,

$$
q_{L} \simeq \sum_{i=1}^{n} \frac{\partial\left(\bar{\theta}_{i} \cdot \Delta z\right)}{\partial t}=\sum_{i=1}^{n} \frac{\partial w_{i}}{\partial t}=\frac{\partial w_{L}}{\partial t} \ldots . . . . \cdot
$$

serido $W_{i}\left(=W_{1}, W_{2}, W_{3}, \ldots, W_{n}\right)$ as quantidades de ägua armaze nada pelas diversas camadas e $W_{L}$ a quantidade de āgua armaze nada pelo solo da superfície até a profundidade L. Nestascir cunstâncias, a equạ̧ão (9) se torna,

$$
[K(\theta)]_{L}=\frac{\frac{\partial W_{L}}{\partial t}}{\left(\frac{\partial \psi}{\partial z}\right)_{L}} \cdot . \cdot \cdot \cdot . . . . . .
$$

Assim, ao invés de se calcular $\partial \theta / \partial t$ para cada camada nos diversos tempos, calcula-se diretamente. $\partial W_{L} / \partial t$ a partir de grä ficos de $W_{L}$ 'versus $t$.

Neste trabalho, os valores de $\partial \psi / \partial z$ para as diversas profundidades foram obtidos a partir das leituras dos tensiómetros em função do tempo, e $\partial W_{L} / \partial t$ por meio de perfís de umidade elaborados com estas leituras e as curvas de retenção para cada profundidade do solo. 


\section{RESULTADOS E DISCUSSÃO}

\subsection{Anālise fĩsica do solo em estudo}

A caracterização física de dois perfís do solo da àrea em estudo é apresentada na Tabela 1. A classe tex“ tural deste solo para os dois'perfís estudados foi franco-are nosa para a camada 0 - $15 \mathrm{~cm}$. Para as demais camadas a classe textural foi franco-argilo-arenosa. Alēm da anälise mecánica também são apresentados, nesta tabela, dados de densidade global e porosidade. Como se pode notar ambos os perfís são praticamente homogêneos em profundidade, o que é confirma do pelos valores da média, desvio padrão da média e intervalo de confiança da média ao nível de $95 \%$ de probabilidade (nove repetições), das características físicas do solo, apresentados na Tabela 2 . 


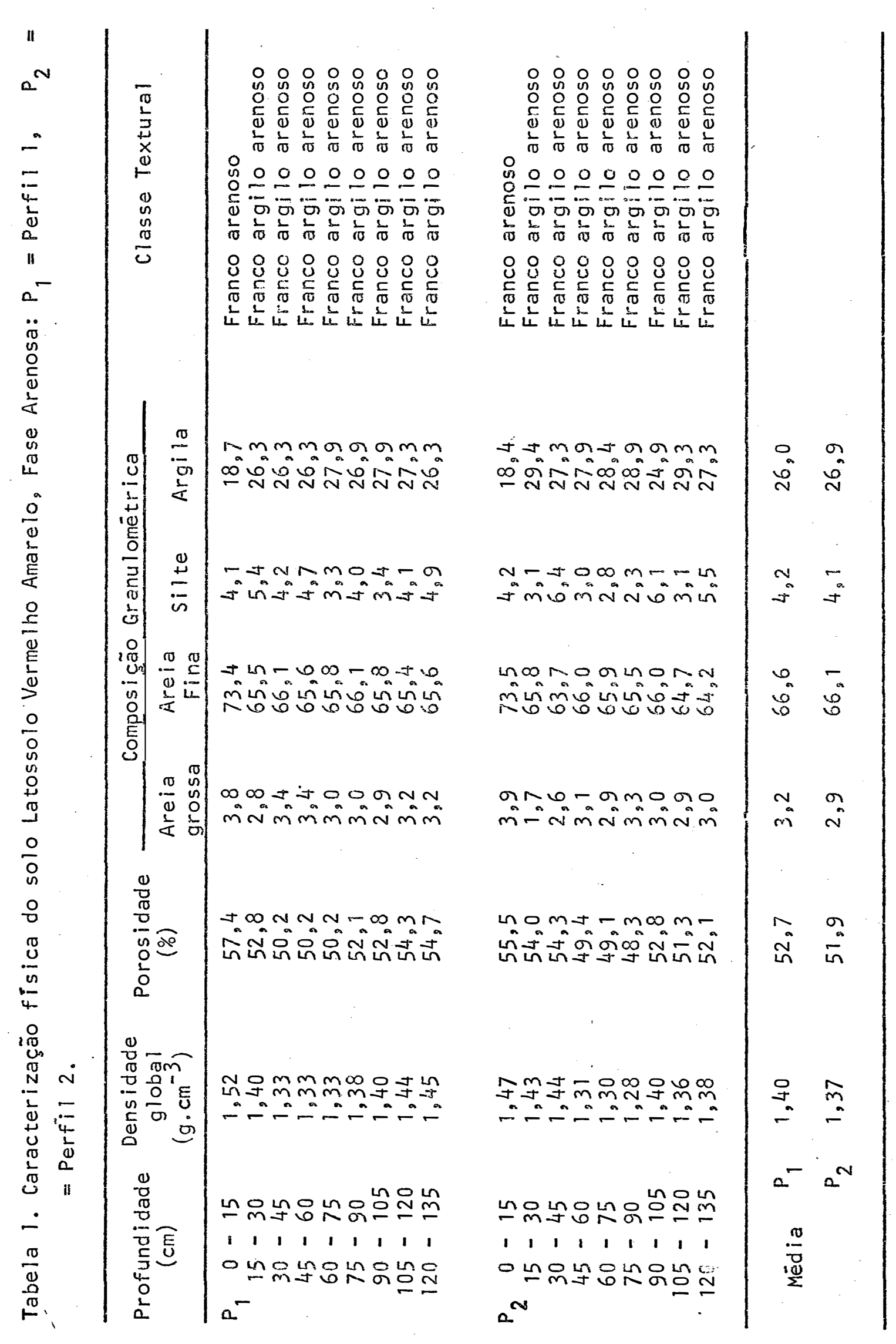


Tabela 2. Média $(\bar{x})$, desvio padrão da mëdia $(s \bar{x})$ e intervalo de confiança de média (IC) ao nivel de $95 \%$ de probabilidade (9 repetições) das caracteristicas físicas do solo estudado.

\begin{tabular}{|c|c|c|c|c|c|c|}
\hline & \multicolumn{6}{|c|}{ Perfis } \\
\hline & \multicolumn{3}{|c|}{$\mathrm{P}_{1}$} & \multicolumn{3}{|c|}{$\mathrm{P}_{2}$} \\
\hline & $\bar{x}$ & $s \bar{x}$ & IC & $\bar{x}$ & $s \ddot{x}$ & IC \\
\hline $\begin{array}{l}\text { Densidade global } \\
\left(\mathrm{g} \cdot \mathrm{cm}^{-3}\right)\end{array}$ & 1,40 & 0,02 & 0,05 & 1,37 & 0,02 & 0,05 \\
\hline $\begin{array}{l}\text { Porosidade } \\
\qquad(\%)\end{array}$ & 52,74 & $0,8 i$ & 1,83 & 51,87 & 0,84 & 1,90 \\
\hline $\begin{array}{l}\text { Areia Grossa } \\
(\%)\end{array}$ & 3,19 & 0,10 & 0,23 & 2,93 & 0,20 & 0,45 \\
\hline $\begin{array}{l}\text { Areia Fina } \\
\qquad(\%)\end{array}$ & 66,59 & 0,86 & 1,94 & 66,14 & 0,96 & 2,17 \\
\hline $\begin{array}{l}\text { Silte } \\
(\%)\end{array}$ & 4,23 & 0,23 & $0,52^{-}$ & 4,86 & 0,52 & 1,18 \\
\hline $\begin{array}{l}\text { Argi ia } \\
(\%)\end{array}$ & 25,99 & 0,94 & 2,12 & 26,07 & 1,15 & 2,60 \\
\hline
\end{tabular}


5.2. Curvas de retenção da ägua no solo

Os resultados de umidade volumétrica do soio $\left(\mathrm{cm}^{3} \mathrm{H}_{2} \mathrm{O} / \mathrm{cm}^{3}\right.$ solo) em função do potencial matricial $\left(\mathrm{cm} \mathrm{H}_{2} \mathrm{O}\right)$ das nove profundidades são apresentados na Figura 6 . A umidade de saturação média dos perfís variou de 0,38 a $0,43 \mathrm{~cm}^{3} \cdot \mathrm{cm}^{-3}$. Na mesma figura estão incluídos os intervalos de confiança da média ao nível de $95 \%$ de probabilidade (seis repetições) oṣ quais estão tabulados na Tabela 3 juntamente com os valores da média e do desvio padrão da média. Foram calculados também os coeficientes de variação para todo o perfil com un valor médio de $5,6 \%$ na faixa de tensão de 0 a $200 \mathrm{~cm}$ de ägua (utilizando-se o funil de placa porosa), um valor médio de $8,3 \%$ para tensões de 300 a $800 \mathrm{~cm}$ de água (empregando-se a pa nela de pressão") è um valor médio de $8,5 \%$ para todo o inter. valo de tensão utilizado ( 0 a $800 \mathrm{~cm}$ de água).

5.3. Condutividade hidráulica de solo saturado

Os testes de infiltração realizados nas 3 parcelas experimentais permitiram a obtenção de um valor médio da condutividade hidráulica saturada de $6,57 \mathrm{~cm} . h_{0} a^{-1}$.

$\because \quad N a$ Tabela 4 são apresentados os valores da con dutividade hidráulica saturada das seis repetições de cada 
.33.
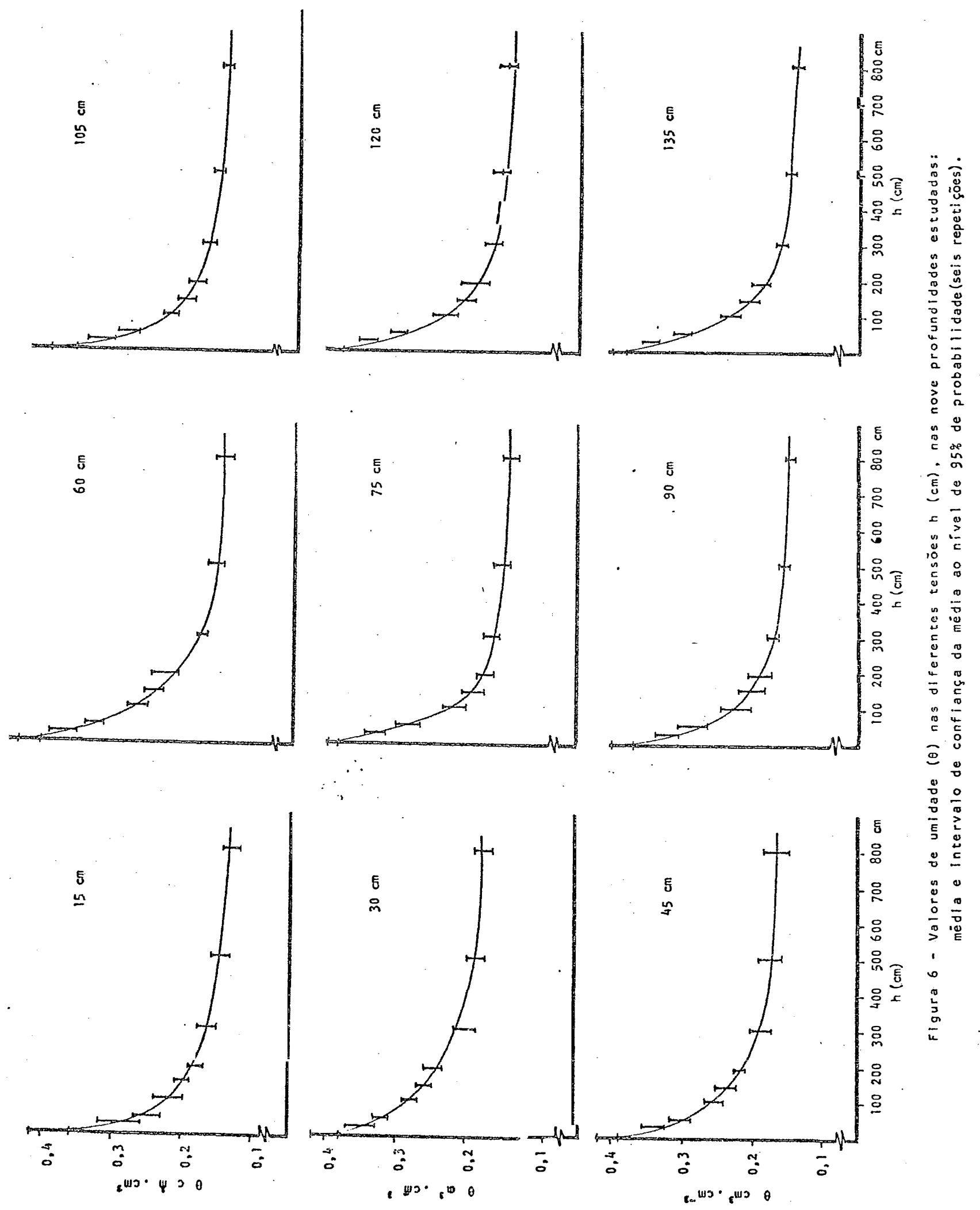


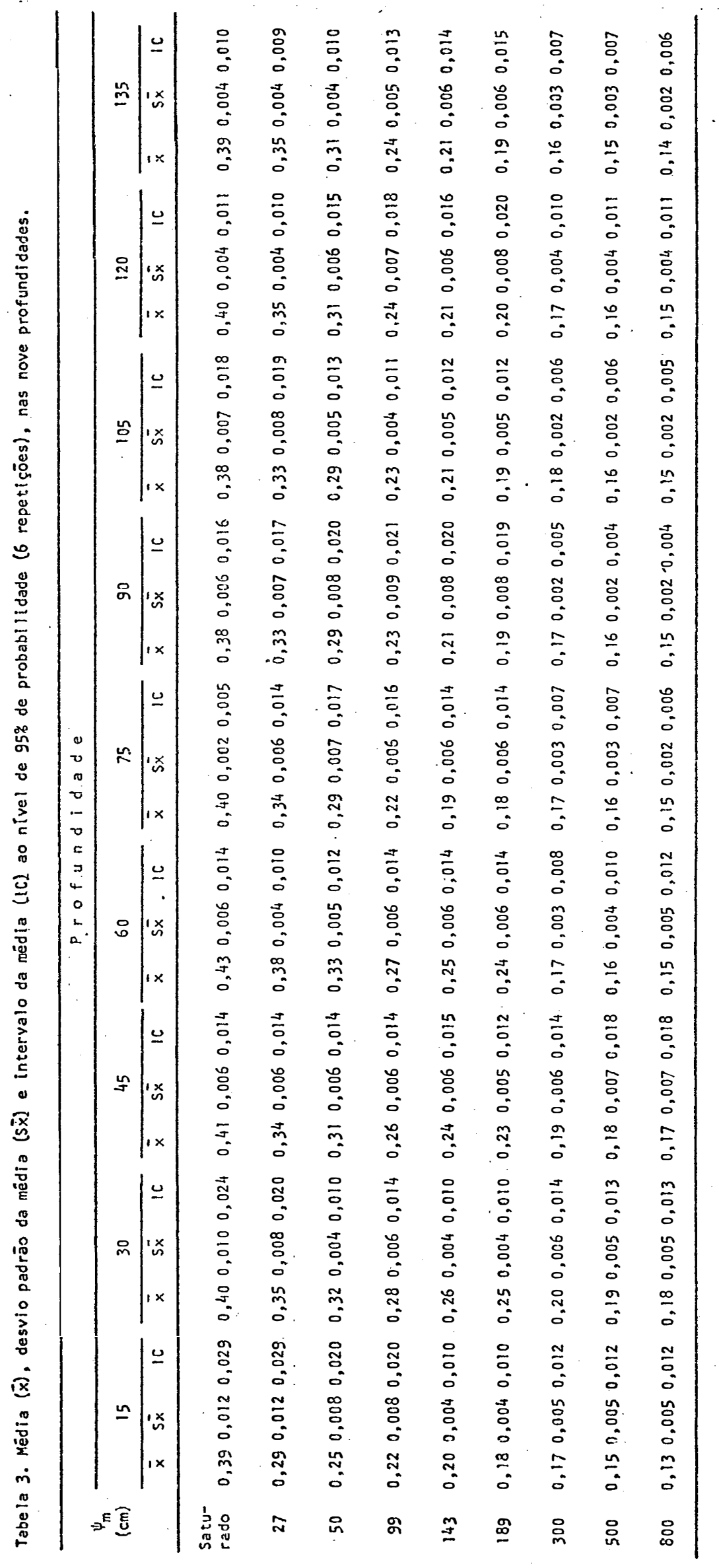


Tabela 4. Valores da condutividade hidráulica saturada (seis repetições) para cada parcela.

\begin{tabular}{|c|c|c|c|}
\hline \multirow{3}{*}{$\begin{array}{l}\text { Amostra } \\
\text { № }\end{array}$} & \multicolumn{3}{|c|}{ Parcelas } \\
\hline & 1 & 2 & 3 \\
\hline & \multicolumn{3}{|c|}{ Infị tração $\left(\mathrm{cmidia}^{-1}\right)$} \\
\hline 1 & 89,1 & 187,2 & 158,4 \\
\hline 2 & 144,0 & 144,0 & 230,4 \\
\hline 3 & 89,1 & 144,0 & 254,8 \\
\hline 4 & 144,0 & 144,0 & 144,0 \\
\hline 5 & 89,1 & 220,2 & 172,8 \\
\hline 6 & 162,0 & 177.9 & 144,0 \\
\hline Mëdia & 119,6 & 169,6 & 184,1 \\
\hline $\begin{array}{l}\text { Coeficiente de } \\
\text { Variação }(\%)\end{array}$ & 28,4 & 18,5 & 25,6 \\
\hline $\begin{array}{l}\text { Coeficiente de } \\
\text { Variação de } 3 \\
\text { Parcelas (\%) }\end{array}$ & & 29,0 & \\
\hline
\end{tabular}


uma das parcelas. Observam-se também a média por parcela e a média geral das três parcelas, com os respectivos coeficien tes de variação. Estes dados indicam que a condutividade hidráulica do solo não possui uma distribuição normal, como já foi observado por NIELSEN et alii (1973).

5.4. Condutividade hidráulica de solo não saturado

Este parâmetro foi obtido como indicado em Material e Métodos (itens 4.2.3., 4.2.4. e 4.2.5.), utilizando a equação (12). Os dados iniciais de potencial matricial e conteúdo de água no solo referentes às três parcelas, para as profundidades de $15,30,45,60,75,90,105,120$ e $135 \mathrm{~cm}$ encontram-se nas Tabelas 5,6 e 7 . As leituras dos tensiômetros foram registradas desde a saturação (infiltração) até 45 dias de drenagem interna.

A partir dos valores de potencial matricial obti dos das leituras dos tensiômetros e das curvas de retenção de água, procedeu-se ao cálculo do armazenamento $\left(W_{L}\right)$ em função do tempo para todas as profundidades. Estes dados se encontram nas Tabelas 8,9 e 10 , correspondentes às parcelas 1,2 e 3 , respectivamente. Comparando-se as três tabelas, ve rifica-se uma similaridade nos dados encontrados. 
Tabela 8. Valores de arnazenamento $\mathrm{H}\left(\mathrm{cm} \mathrm{H}_{2} \mathrm{O}\right)$ para diversos tempos $t(\mathrm{dla})$ e profundidades $(z$, cml durante a redistribulção da água na parcela 1 .

\begin{tabular}{|c|c|c|c|c|c|c|c|c|c|c|}
\hline \multirow{2}{*}{$\begin{array}{l}\text { Tempo } \\
\text { (dias) }\end{array}$} & & \multicolumn{9}{|c|}{ Profundidade $(z, \mathrm{~cm})$} \\
\hline & & 15 & 30 & 45 & 60 & 75 & 90 & 105 & 120 & 135 \\
\hline 0,000 & & 5,850 & 11,850 & 17,985 & 24,390 & 30,315 & 36,060 & 41,805 & 47.745 & 53,610 \\
\hline 0,010 & & 5,550 & 11,370 & 17,250 & 23.430 & 29,130 & 34,650 & 40,200 & 45,900 & 51,555 \\
\hline 0,021 & & 5,250 & 10,980 & 16,680 & 22,800 & 28,425 & 33,750 & 39,120 & 44,700 & 50,205 \\
\hline 0,031 & & 5,070 & 10,740 & 16,365 & 22,440 & 27,960 & 33,210 & 38,430 & 43,950 & 49,380 \\
\hline 0,042 & & 4,875 & 10,500 & 16,020 & 22,020 & 27,450 & 32,520 & 37,650 & 43,050 & 48,405 \\
\hline 0,052 & & 4,770 & 10,350 & 15,780 & 21,750 & 27,075 & 32,055 & 37.035 & 42,405 & 47,685 \\
\hline 0,063 & & 4,650 & 10,170 & 15,495 & 21,375 & 26,625 & 31,545 & 36,420 & 41,745 & 46,950 \\
\hline 0,073 & & 4,575 & 10,005 & 15,285 & 21,135 & 26,310 & 31,110 & 35,910 & 41,130 & 46,260 \\
\hline 0,083 & & 4,425 & 9,825 & 15,000 & 20,820 & 25,890 & 30,660 & 35,430 & 40.605 & 45,705 \\
\hline 0,104 & & 4,380 & 9,750 & 14,820 & 20,595 & 25,575 & 30,255 & 34,905 & 39,975 & 45,000 \\
\hline 0,125 & & 4,350 & 9,675 & 14,655 & 20,235 & 25,155 & 29,730 & $34,230^{\circ}$ & 39,180 & 44,130 \\
\hline 0,167 & & 4,200 & $9,450^{\circ}$ & 14,280 & 19,755 & 24,480 & 28,860 & 33,240 & 38,070 & 42,870 \\
\hline 0,208 & & 4,125 & 9,345 & 14,025 & 19,425 & 24,075 & 28,425 & 32,655 & 37,425 & 42,075 \\
\hline 0,250 & & 4,050 & 9,225 & 13,845 & 19,170 & 23,745 & 28,065 & 32,190 & $36,8 \% 0$ & 41,445 \\
\hline 0,375 & & 3,975 & 9,105 & 13,635 & 18,855 & 23,235 & 27,435 & 31,410 & 35,985 & 40,410 \\
\hline 0,500 & & 3,930 & 9,000 & 13,500 & 18,675 & 22,905 & 27,030 & 30,930 & 35,460 & 39.810 \\
\hline 1.000 & . & 3,780 & 8,655 & 13,035 & 17,910 & 21,885 & 25,815 & 29,535 & 33,660 & 37,665 \\
\hline 1,500 & & 3,675 & 8,445 & 12,720 & 17,445 & 21,165 & 24,915 & 28,485 & 32,415 & 36,240 \\
\hline 2,000 & & 3,570 & 8,220 & 12,345 & 16,920 & 20,520 & 24,195 & 27,675 & 31,470 & 35,175 \\
\hline 3,000 & & 3,450 & 7.950 & 11,925 & 16,305 & 19,680 & 23,160 & 26,535 & 30,135 & 33,705 \\
\hline 4,000 & & 3,375 & 7.755 & 11,625 & 15,945 & 19,215 & 22,635 & 25,965 & 29,490 & 32,970 \\
\hline 5,000 & & 3,300 & 7,575 & 11,370 & 15,570 & 18,750 & 22,080 & 25,380 . & 28,815 & 32,220 \\
\hline 10,000 & & 3,090 & 7,140 & 10,740 & 14,640 & 17,610 & 20,790 & 23,970 & 27,240 & 30,540 \\
\hline 15,000 & & 2,970 & 6,840 & 10,320 & 14,040 & 16,920 & 19,995 & 23,145 & 26,325 & 29,505 \\
\hline 20,000 & & 2,880 & 6,630 & 10,050 & 13,650 & 16,500 & 19,515 & 22,590 & 25.710 & 28,860 \\
\hline 25,000 & & 2,820 & 6,495 & 9,825 & 13,305 & 16,080 & $19,0.50$ & 22,080 & 25,155 & 28,245 \\
\hline 30,000 & & 2,775 & 6,375 & 9,660 & 13.035 & 15,765 & 18,690 & 21,645 & 24,675 & 27,720 \\
\hline 35,000 & & 2.730 & 6,255 & 9,480 & 12,780 & 15,480 & 18,375 & 21,300 & 24,300 & 27,300 \\
\hline 40,000 & & 2,700 & 6,165 & 9,345 & 12,570 & 15,255 & 18,135 & 21,045 & 24,030 & 27,000 \\
\hline 45,000 & & 2,670 & 6,120 & 9,270 & 12,450 & 15,120 & 17,985 & 20,865 & 23,835 & 26,790 \\
\hline
\end{tabular}


Tabela 9. Valores de armazenamento $W\left(\mathrm{~cm} \mathrm{H}_{2} \mathrm{O}\right)$ para diversos tempos $t$ (dia) e profundidades $(2, \mathrm{~cm})$ durante a redistribuição da àgua na parcela 2.

\begin{tabular}{|c|c|c|c|c|c|c|c|c|c|}
\hline \multirow{2}{*}{$\begin{array}{l}\text { Tempo } \\
\text { (dias) }\end{array}$} & \multicolumn{9}{|c|}{ Profundidade $(z, \mathrm{~cm})$} \\
\hline & 15 & 30 & 45 & 60 & 75 & 90 & 105 & 120 & 135 \\
\hline 0,000 & 5,850 & 11,850 & 17.985 & 24,390 & 30,315 & 36,060 & 41,805 & 47,745 & 53,610 \\
\hline 0,010 & 4,950 & 10,680 & 16,485 & 22,635 & 28,365 & 33,990 & 39,615 & 45,435 & 51,165 \\
\hline 0,021 & 4,380 & 10,005 & 15,555 & 21,555 & 27,060 & 32,535 & 38,055 & 43,830 & 49,485 \\
\hline 0,031 & 4,230 & 9.735 & 15,090 & 20,895 & 26,250 & 31,575 & 36,975 & 42,600 & 48,225 \\
\hline 0,042 & 4,200 & 9,630 & 14,880 & 20,505 & 25,755 & 30,975 & 36,255 & 41,805 & 47,385 \\
\hline 0,052 & 4,155 & 9,435 & 14,610 & 20,115 & 25,245 & 30.345 & 35,475 & 40.950 & 46,455 \\
\hline 0,063 & 4,080 & 9,330 & 14,460 & 19,890 & 24,960 & 29,985 & 35,055 & 40,485 & 45,915 \\
\hline 0,073 & 4,050 & 9,270 & 14,295 & 19.650 & 24,630 & 29,580 & 34,605 & 40,005 & 45,405 \\
\hline 0,083 & 4,005 & 9,195 & 14,175 & 19,455 & 24,375 & 29,250 & 34,200 & 39.525 & 44,895 \\
\hline 0,104 & 3,975 & 9,105 & 13,980 & 19,185 & 24,060 & 28,830 & 33,660 & 38,880 & 44,160 \\
\hline 0,125 & $3,930^{\circ}$ & 9,030 & 13,860 & 18,960 & 23,730 & 28,380 & 33,150 & 38.325 & 43,530 \\
\hline 0,167 & 3,900 & 8,925 & 13,605 & 18,555 & $23 ; 205$ & 27,705 & 32,235 & 37.215 & 42,240 . \\
\hline 0,208 & 3,825 & 8,775 & $\cdot 13,350$ & $18,22.5$ & 22,755 & 27,135 & 31,605 & 36,480 & 41,310 \\
\hline 0,250 & 3,780 & 8,685 & 13,185 & 18,015 & 22,440 & 26,760 . & 31,110 & 35,910 & 40,710 \\
\hline 0,375 & 3,750 & 8,580 & 12,960 & 17,685 & 22,005 & 26,175 & 30.345 & 34,995 & 39,570 \\
\hline 0,500 & 3,705 & 8,505 & 12,855 & 17,505 & 21,705 & 25,830 & 29,955 & 34,530 & 38,985 \\
\hline 1,000 & 3,630 & 8,160 & 12,210 . & 16,635 & 20,415 & 24,240 & 28,110 & 32,340 & 36,510 \\
\hline 1,500 & 3,450 & 7,830 & 11,760 & 16,035 & 19,635 & 23,355 & $2 i, 075$ & 31,095 & 34,955 \\
\hline 2,000 & 3,375 & 7,680 & 11,535 & 15,735 & 19,185 & 22,755 & 26,325 & 30,255 & 34,035 \\
\hline 3,000 & 3,255 & 7,410 & 11,190 & 15,240 & 18,570 & 22,020 & 25,470 & 29,190 & 32,790 \\
\hline 4,000 & 3,180 & 7,260 & 10,965 & 14,940 & 18,165 & 21,540 & 24,930 & 28,530 & 32,010 \\
\hline 5,000 & 3,150 & 7,200 & 10,875 & 14,775 & 17,925 & 21,225 & 24,555 & 28,080 & 31,530 \\
\hline 10,000 & 3,000 & 6,855 & 10.335 & 14,040 & 17,040 & 20,190 & 23,415 & 26,745 & 30,045 \\
\hline 15,000 & 2,925 & 6,675 & 10,080 & 13,680 & 16,560 & 19,635 & 22,785 & 26,055 & 29,235 \\
\hline 20,000 & 2,850 & 6,480 & 9,810 & 13,335 & 16,185 & 19,200 & $.22,275$ & 25,470 & 28,590 \\
\hline 25,000 & 2,775 & 6,375 & 9,630 & 13,035 & 15,855 & 18,825 & 21,855 & 25,005 & 28,080 \\
\hline 30,000 & 2,730 & 6,255 & 9.480 & 12,855 & 15,645 & 18,570 & 21.570 & 24,690 & 27,705 \\
\hline 35,000 & 2,700 & 6,180 & 9,375 & 12,675 & 15,435 & 18.315 & 21,285 & 24,360 & 27.330 \\
\hline 40,000 & 2,670 & 6,120 & 9,300 & 12,525 & 15,255 & 18,120 & 21,045 & 24,075 & 27,015 \\
\hline 45,000 & 2,634 & 6,090 & 9,240 & $12,1,20$ & 15,120 & 17,970 & 20,850 & 23,850 & 26,775 \\
\hline
\end{tabular}


Tabela 10. Valores de armazenamento $W\left(\mathrm{~cm} \mathrm{H}_{2} \mathrm{O}\right)$ para diversos tempos $t$ (dia) e profundidades $(z, \mathrm{~cm})$ durante a redistribuição da água na parcela 3.

\begin{tabular}{|c|c|c|c|c|c|c|c|c|c|c|}
\hline \multirow{2}{*}{$\begin{array}{l}\text { Tempo } \\
\text { (dias) }\end{array}$} & & \multicolumn{9}{|c|}{ Profundidade $(z, c m)$} \\
\hline & . & 15 & 30 & 45 & 60 & 75 & 90 & 105 & 120 & 135 \\
\hline 0,000 & & 5,850 & 11,850 & 17,985 & 24,390 & 30,315 & 36,060 & 41,805 & 47,745 & 53,160 \\
\hline 0,010 & & 4,680 & 10,050 & 15,330 & 21,255 & 26,655 & 32,025 & 37.395 & 42,975 & 48,525 \\
\hline 0,021 & & 4,425 & 9,675 & 14,895 & 20,595 & 25,695 & 30,795 & 36,075 & 41,595 & 47,025 \\
\hline 0,031 & & 4,380 & 9,555 & 14,580 & 20,130 & 25,110 & 30,180 & 35,355 & 40,785 & 46,185 \\
\hline 0,042 & & 4,275 & 9,375 & 14,355 & 19,830 & 24,780 & 29.730 & 34,830 & 40,230 & 45,480 \\
\hline 0,052 & & 4,230 & 9,300 & 14,175 & 19.595 & 24,495 & 29,415 & 34,440 & 39,765 & 44,895 \\
\hline 0,063 & & 4,200 & 9,180 & 14,010 & 19,260 & 24.135 & 28,965 & 33,915 & 39,195 & 44,250 \\
\hline 0,073 & & $-4,170$ & 9,090 & 13.815 & 18,990 & 23,760 & 28,560 & 33,435 & 38,655 & 43,680 \\
\hline 0,083 & & 4,125 & 9,000 & 13,680 & 18,810 & 23,490 & 28,215 & 33,045 & 38,235 & 43,215 \\
\hline 0,104 & & 4,050 & 8,880 & 13,455 & 18,480 & 23,130 & 27,780 & 32,505 & 37.635 & 42,465 \\
\hline 0,125 & & 3,975 & 8,775 & 13,275 & 18,255 & 22,875 & 27,405 & 32,055 & 37.110 & 41,910 \\
\hline 0,167 & & 3,930 & 8,655 & 13,080 & 17,955 & 22,455 & $.26,880$ & 31,410 & 36,285 & 41,055 \\
\hline 0,208 & & 3,825 & 8,475 & 12,825 & 17,625 & 22,005 & $26,38.5$ & 30,735 & 35,535 & 40,110 \\
\hline 0,250 & & 3,780 & 8,400 & 12,720 & 17,370 & 21,765 & 26,085 & 30,360 & 35,130 & 39,555 \\
\hline 0,375 & & 3,750 & 8,295 & 12,495 & 17,175 & 21,255 & 25,380 & 29,430 & 33.960 & 38,265 \\
\hline 0,500 & & 3,720 & 8,190 & 12,315 & 16,965 & 20,865 & 24,690 & 28,665 & 32,985 & 37,140 \\
\hline 1,000 & & 3,630 & 3,010 & 12,060 & 16,410 & 20,130 & 23,910 & 27,630 & 31,785 & 35,640 \\
\hline 1,500 & & 3,480 & 7,710 & 11,640 & 15,840 & 19,365 & 22,995 & 26,595 & 30,525 & 34,275 \\
\hline 2,000 & . & 3,420 & 7,590 & 11,415 & 15,540 & 18,990 & 22,560 & 26,085 & $29 ; 835$ & 33,510 \\
\hline 3,000 & & 3,300 & 7,350 & 11,100 & 15,120 & 18,390 & 21,810 & 25,200 & 28,830 & 32,355 \\
\hline 4,000 & & 3,225 & 7,200 & 10,875 & 14,815 & 17,985 & 21,315 & 24,645 & 28,170 & 31,650 \\
\hline 5,000 & & 3,150 & 7,080 & 10,695 & 14,565 & 17,685 & 20,955 & 24,255 & 27,705 & 31,110 \\
\hline 10,000 & & 3,000 & 6,750 & 10,200 & 13,875 & 16,800 & 19,920 & 23,070 & 26,355 & 29,655 \\
\hline 15,000 & & 2,880 & 6,510 & 9,885 & 13,445 & 16,305 & 19,335 & 22,455 & 25,680 & 28,905 \\
\hline 20,000 & & 2,820 & 6,420 & 9,720 & 13,170 & 15,960 & 18,960 & 22,035 & 25,185 & 28,350 \\
\hline 25,000 & & 2,775 & 6,300 & 9.525 & 12,945 & 15.705 & 18,630 & 21,660 & 24.750 & 27,855 \\
\hline 30,000 & & 2.730 & 6,195 & 9.375 & 12,705 & 15,435 & 18,330 & 21,330 & 24,390 & 27.465 \\
\hline 35,000 & & 2,685 & 6,105 & 9,255 & 12,555 & 15,255 & 18,135 & 21,105 & 24,150 & 27,195 \\
\hline 40,000 & & 2,655 & 6,045 & 9.165 & 12,390 & 15,060 & 17,910 & 20,850 & 23,880 & 26,910 \\
\hline 45,000 & & 2,625 & 6,000 & 9,090 & 12,270 & 14,925 & 17,745 & 20,670 & 23,670 & 26,670 \\
\hline
\end{tabular}


Para o cálculo de $K(\theta)$ pela equação (12) determinou-se inicialmente a variação do armazenamento com o tempo ( $\partial W_{L} / \partial t$ ) para diferentes tempos e profundidades ( $\left.L\right)$, traçando as tangentes das curvas de armazenamento versus tempo. os dados obtidos, referentes as três parcelas, estão apresentados nas Tabelas 11,12 e 13. Estes valores são as densida des de fluxo $\left(q_{L}\right)$, como indica a equação (11), para as profun didades $15,30,45,60,75,90,105,120$ e $135 \mathrm{~cm}$ durante o processo de redistribuiçäo da água do solo para o período considerado. Observa-se que nas três parcelas, na camada de $15 \mathrm{~cm}$ de profundidade, os valores de fluxo caem bruscamente de $29,301 \mathrm{~cm} \cdot \mathrm{dia}^{-1}, 29,866 \mathrm{~cm} . \mathrm{dia}^{-1}$ e $27.804 \mathrm{~cm} \cdot \mathrm{dia}^{-1}$ com quin ze minutos após a saturação, para $0,206 \mathrm{~cm}$.dia-1, $0,144 \mathrm{~cm} . \mathrm{dia}^{-1}$ e $0,125 \mathrm{~cm} . \mathrm{dia}^{-1}$ com um dia, chegando a valores bem baixos como $0,005 \mathrm{~cm} \cdot \mathrm{dia}^{-1}, 0,006 \mathrm{~cm} \cdot \mathrm{dia}^{-1}$ e $0,006 \mathrm{~cm} \cdot \mathrm{dia}^{-1}$ aos quarenta dias.

$0 s$ gradientes de potencial total da água $(\partial \psi / \partial z)_{L}$, indicados na equação (12), encontram-se nas Tabelas 14,15 e 16. Seus valores foram obtidos através da seguinte expressão:

$$
\left.\left(\frac{\partial \psi}{\partial z}\right)_{L} \simeq \frac{\Delta \psi}{\Delta z}\right|_{L}=\frac{\psi_{L}-15^{-} \psi_{L}+15}{30} \ldots \ldots .
$$

Para as profundidades dos extremos, isto é, $z=15$ e $z=135 \mathrm{~cm}$, a fórmula utilizada.foi diferente da expressão (13), pelo fato de não se ter tensiômetros em $z=0$ e $z^{\prime}=150 \mathrm{~cm}$. 
.44.

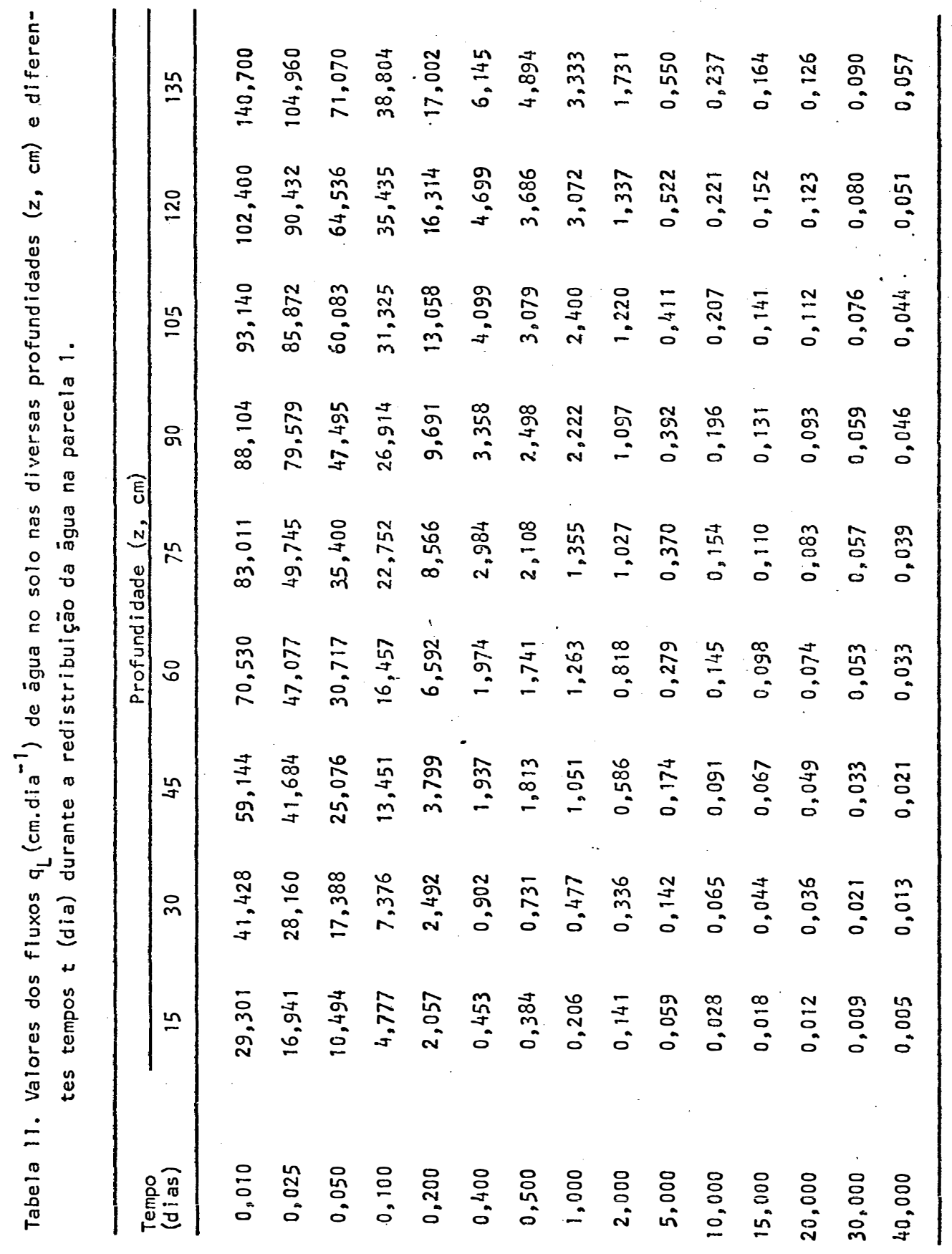




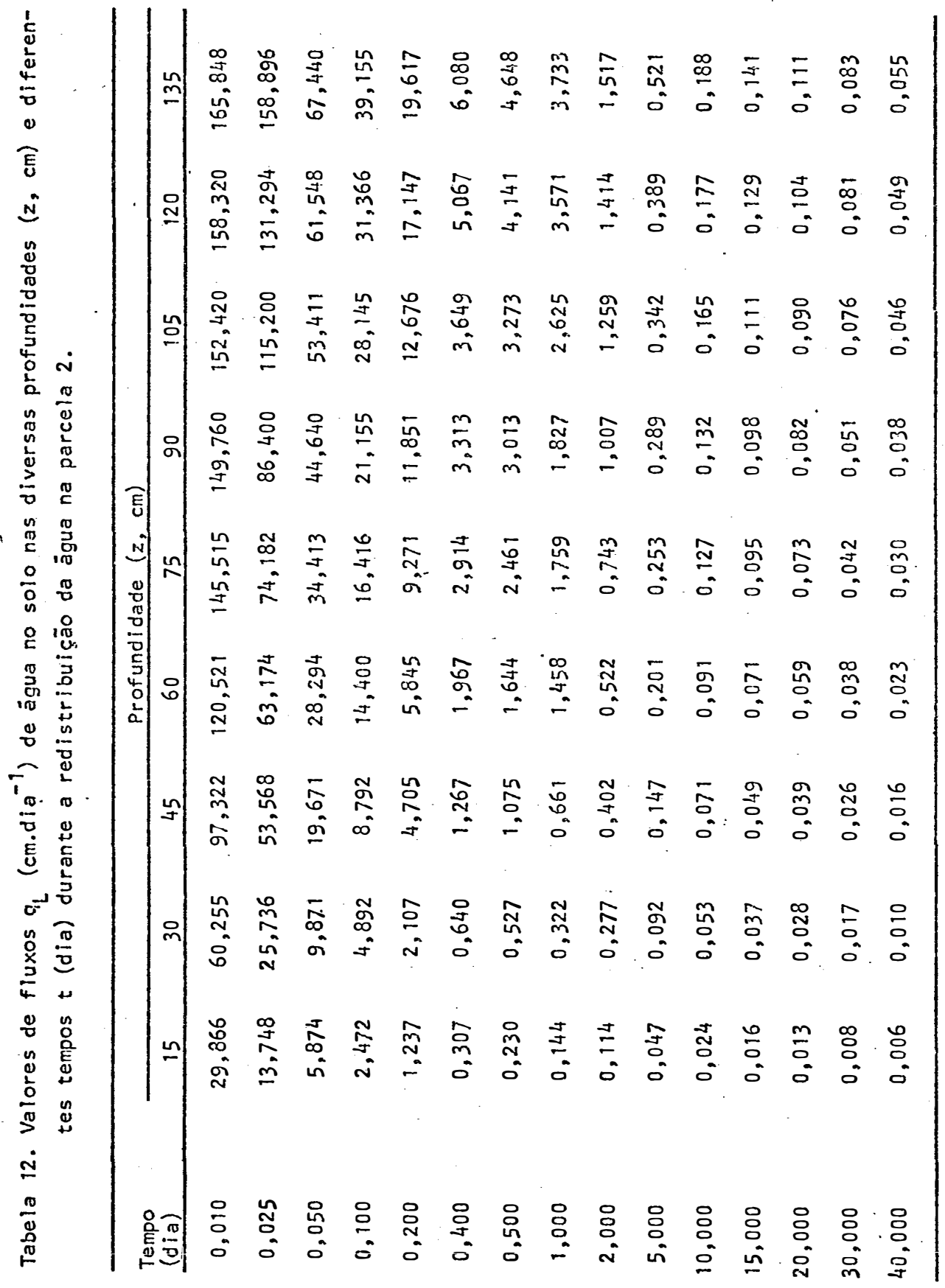


.46.

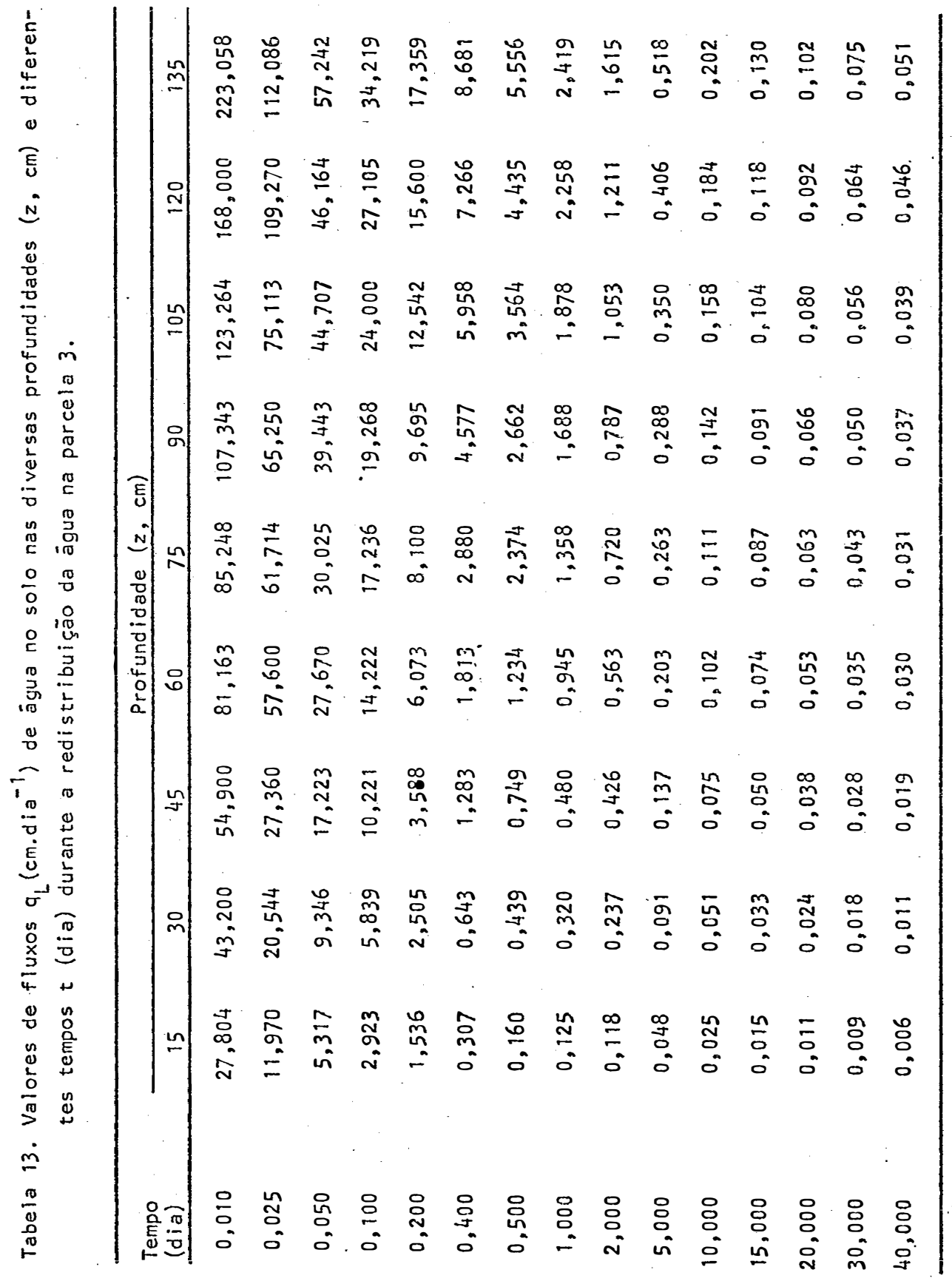




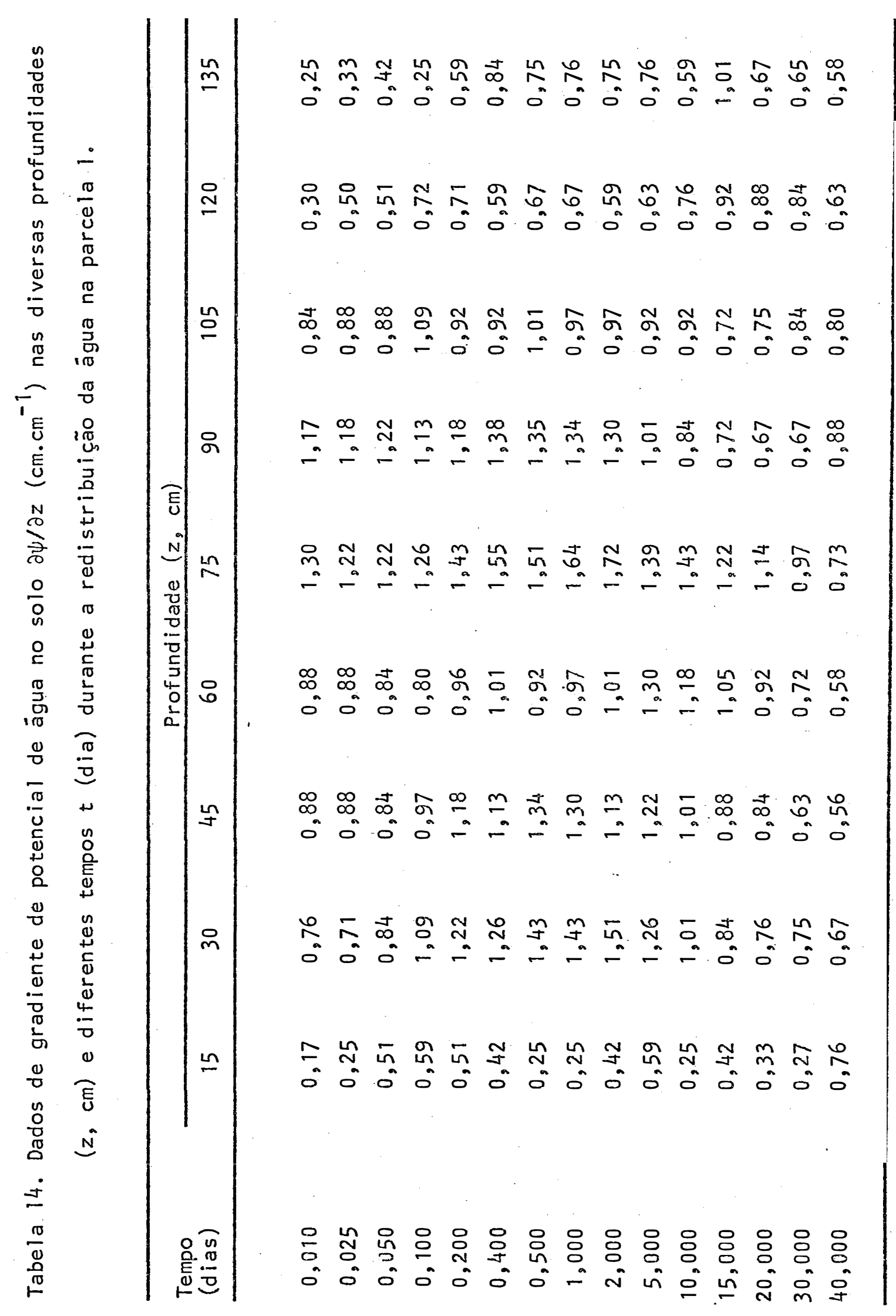




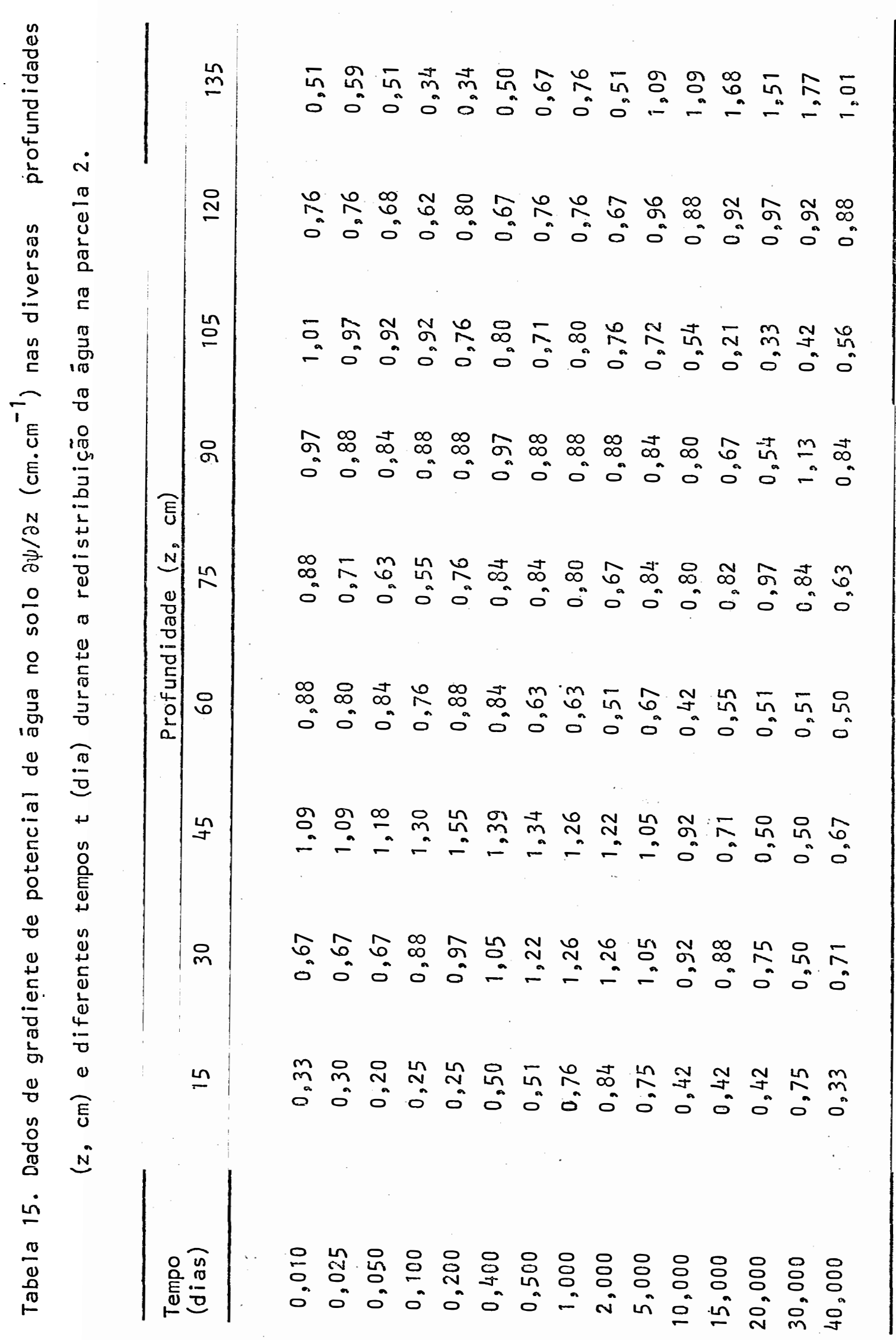




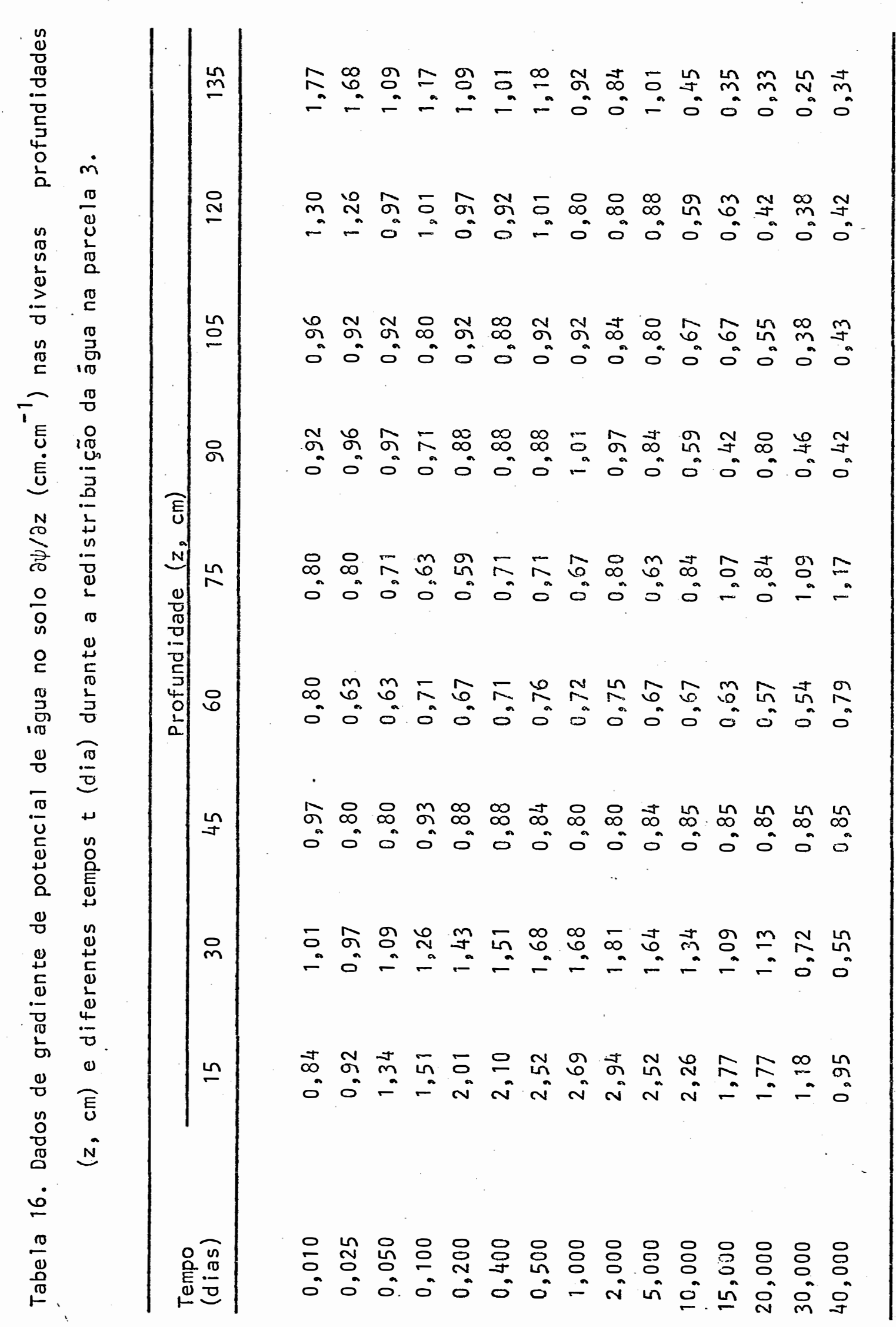


Assim, para $z=15 \mathrm{~cm}$, utilizou-se:

$$
\left.\frac{\Delta \psi}{\Delta z}\right|_{L}=\frac{\psi_{L}-\psi_{L}+15}{15} . . . . . . .
$$

enquanto que para $z=135 \mathrm{~cm}$,

$$
\left.\frac{\Delta \psi}{\Delta z}\right|_{L}=\frac{\psi_{L}-15^{-\psi_{L}}}{15} \quad . . . . . . .
$$

Observa-se que na camada $0-15 \mathrm{~cm}$ de profundidade o gradiente de potencial apresenta valores mais baixos que nas outras profundidades.

os valores da condutividade hidrāulica calcula dos segundo a equação (12) referentes às parcelàs em estudo, são apresentadós nas Tabelas 17,18 e 19. Uma anālise superficial dos dados indica que aos $15 \mathrm{~cm}$ de profundidade, aos quin ze minutos a condutividade foi de $172,358 \mathrm{~cm} \cdot \mathrm{dia}^{-1}, 90,503 \mathrm{~cm} \cdot \mathrm{dia}^{-1}$ e $33,100 \mathrm{~cm} \cdot \mathrm{dia}^{-1}$; com um dia foi de $0,824 \mathrm{~cm} \cdot \mathrm{dia}^{-1}, 0,189 \mathrm{~cm} \cdot \mathrm{dia}^{-1}$ e $0,046 \mathrm{~cm} . d i a^{-}$e com quarenta dias abaixou para $0,007 \mathrm{~cm} . \mathrm{dia}^{-1}$, $0,018 \mathrm{~cm} \cdot \mathrm{dia}^{-1}$ e $0,006 \mathrm{~cm} \cdot \mathrm{dia}^{-1}$, respectivamente, para as par celas 1,2 e 3 .

Com o objetivo de dar uma visão geral do processo de redistribuição da āgua neste solo, apresentam-se na Figura 7 os valores de potencial total de água do solo obtidos por meio de tensiômetros, referentes à parcela l em funçäo do tempo e das profundidades estudadas abe que 
.51.

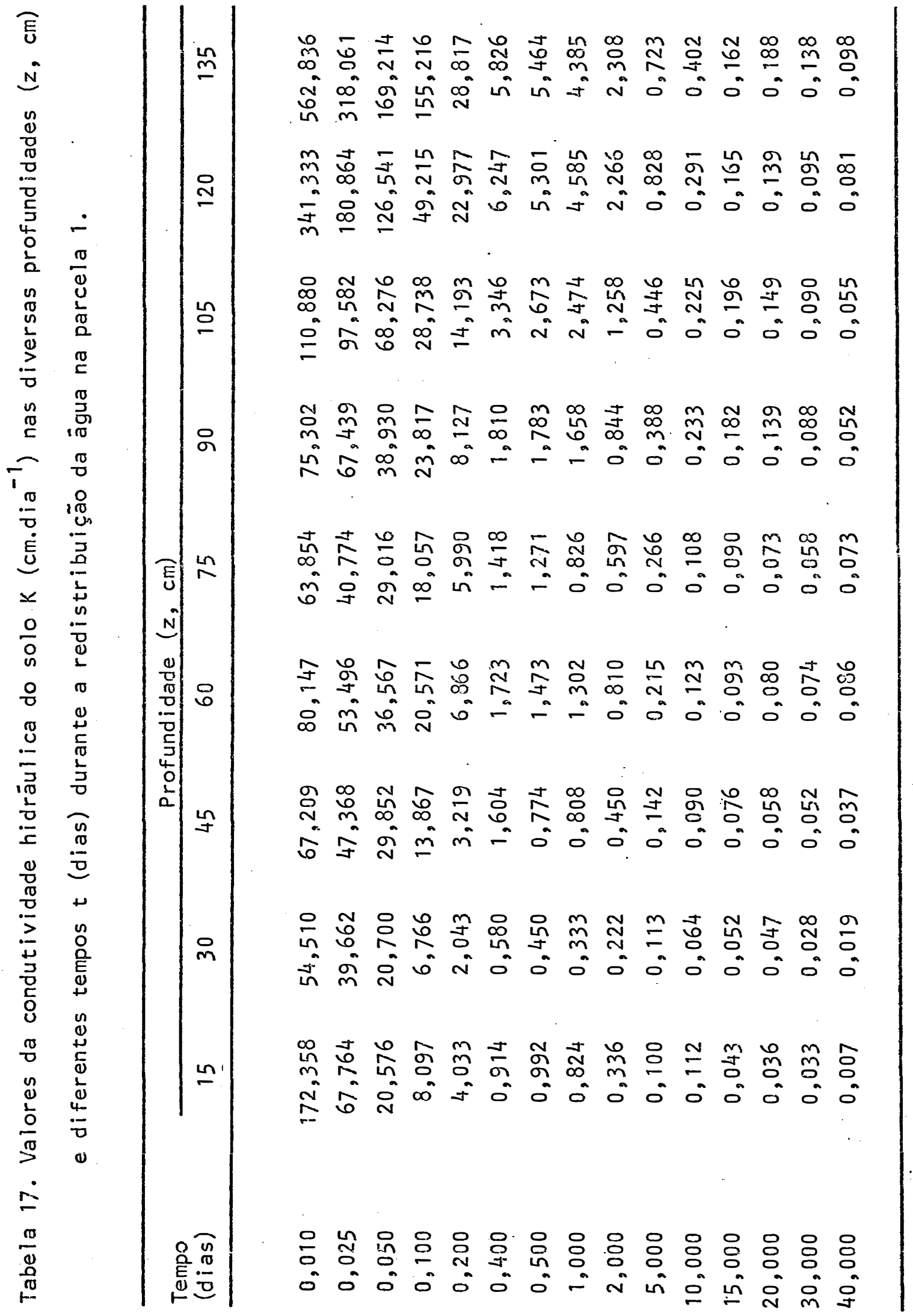




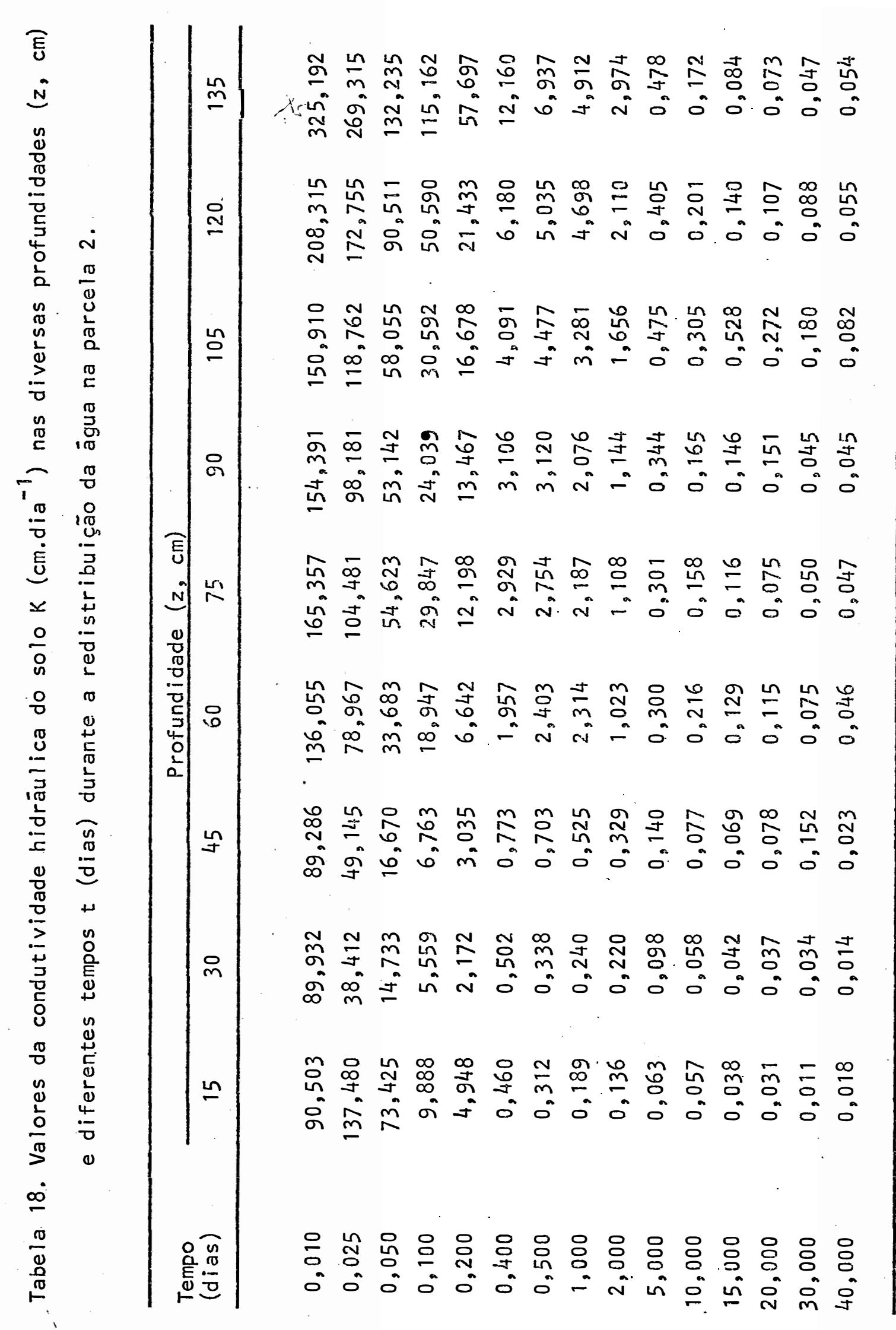




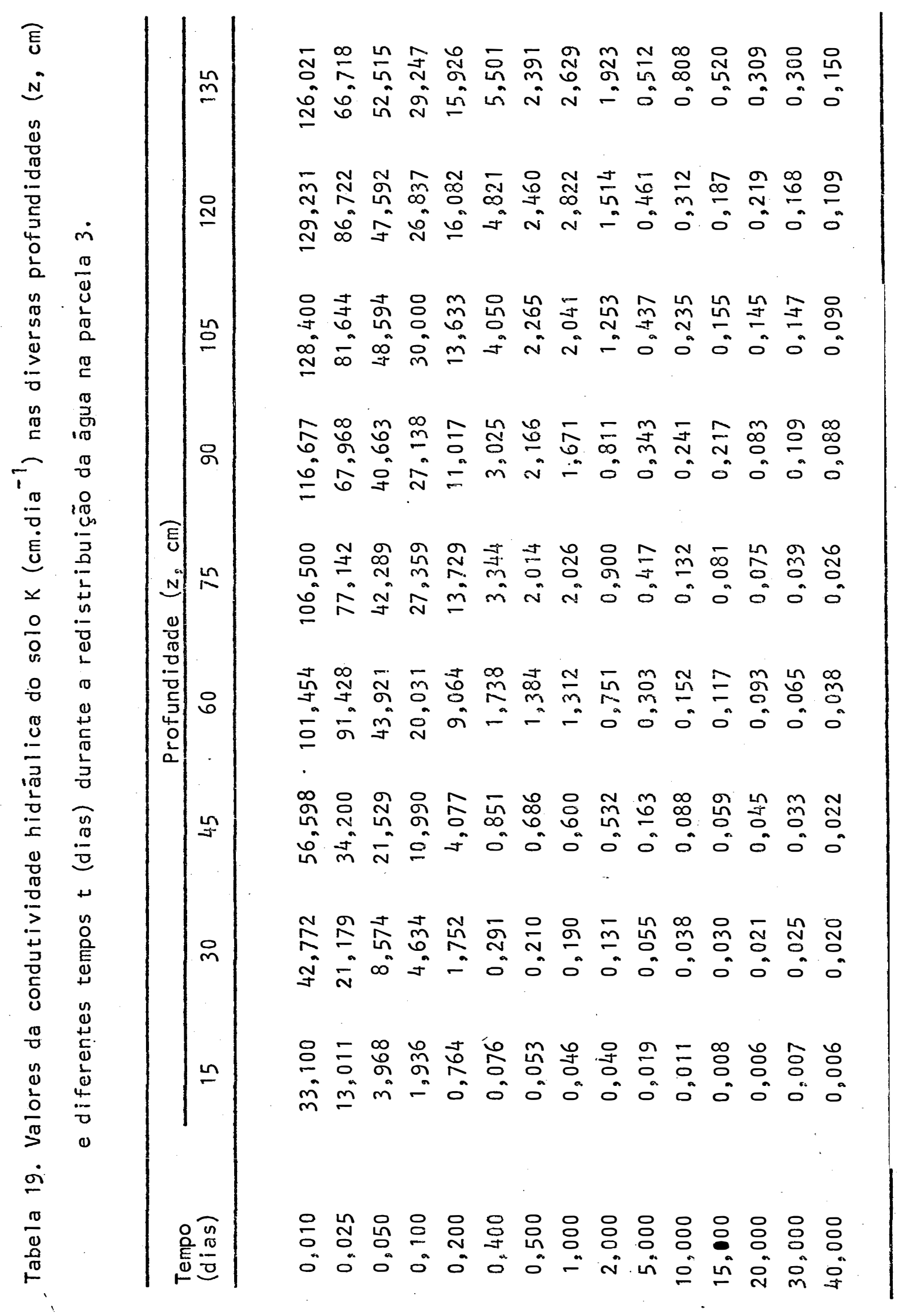


.54.

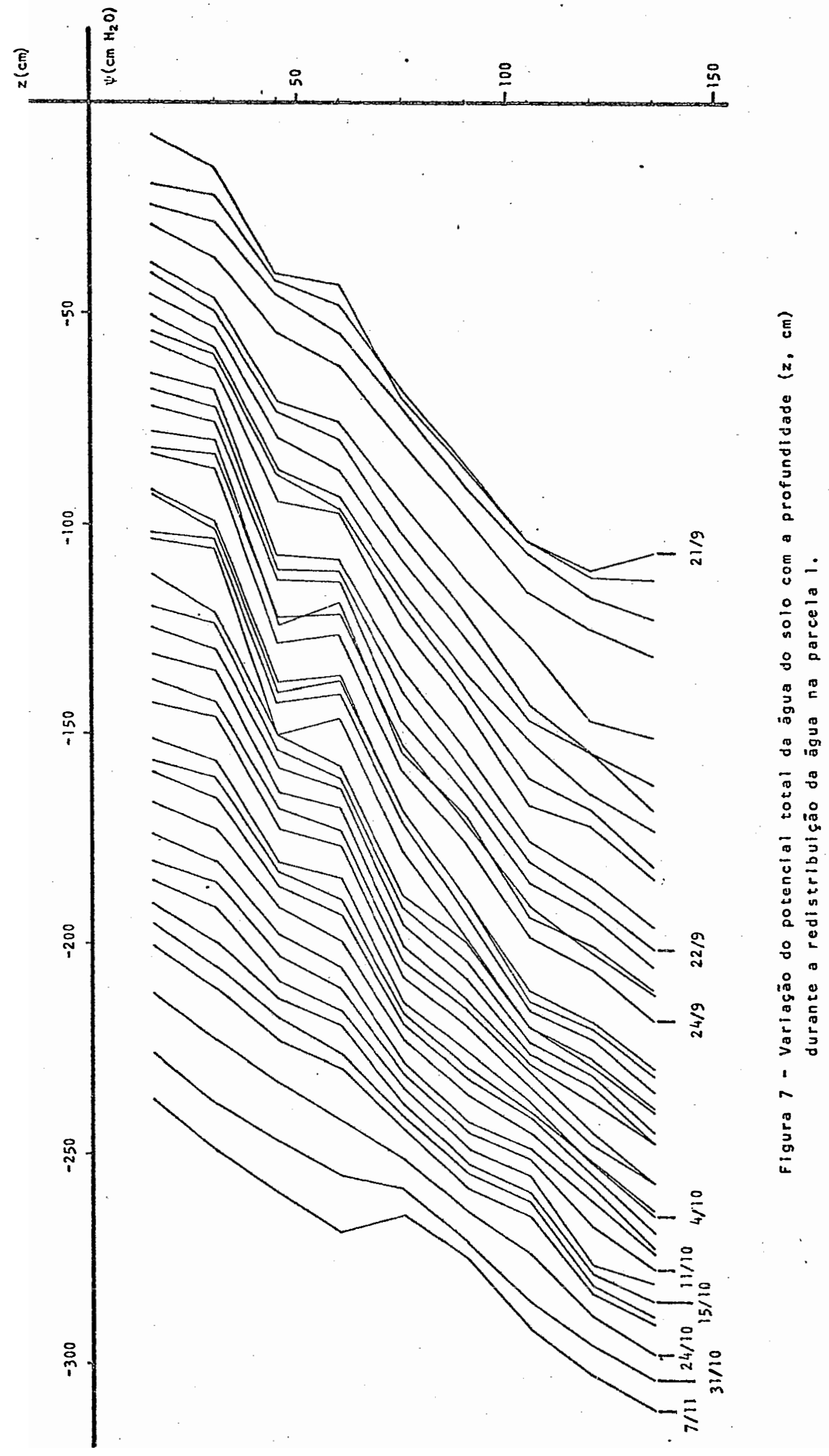




\begin{tabular}{|c|c|c|c|c|c|c|c|c|c|c|c|c|c|c|c|c|c|c|c|c|c|c|}
\hline .' & $\pi$ & & 이 & & $\frac{\sigma_{0}}{1}$ & & & & & of & c & 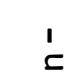 & & $\stackrel{\stackrel{\sim}{\sim}}{ }$ & $\ddot{m}$ & $\pi$ & $\stackrel{\pi}{E}$ & & 0 & $\stackrel{n}{0}$ & $\dot{0}$ & cl \\
\hline 0 & & & $\pi$ & .0 & $\underset{\sigma}{\stackrel{\Xi}{E}}$ & & $\stackrel{0}{0}$ &. & $0^{\circ}$ & ᄃ & $\pi$ & $5_{4}^{3}$ & 0 & - & 6 & $\overline{0}$ & $\begin{array}{l}n \\
0 \\
0\end{array}$ & & 0 & . & $\dot{a}$ & $\dot{u}$ \\
\hline$\stackrel{0}{E}$ & $\bar{\pi}$ & & $\stackrel{n}{0}$ & $\begin{array}{l}0 \\
\frac{1}{5}\end{array}$ & $\frac{\geq}{4}$ & & $\frac{1}{\pi}$ & $\frac{4}{-}$ & $\stackrel{n}{z}$ & $\tilde{\sigma}_{\sigma}^{u}$ & $\begin{array}{l}\sigma \\
\sigma\end{array}$ & $\begin{array}{l}0 \\
\frac{1}{a}\end{array}$ & $\frac{0}{\sigma}$ & in & $m$ & 1 & $E$ & & ర్ & $\stackrel{\vec{J}}{\vec{u}}$ & 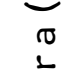 & $\frac{\pi}{0}$ \\
\hline$E$ & - & & $n$ & ${ }_{0}^{4}$ & $\dot{0}$ & & $\sigma$ & $\stackrel{2}{>}$ & $\begin{array}{l}n \\
\vdots \\
\vdots\end{array}$ & 0 & ז & $n$ & $>$ & ח & $\ddot{\sigma}$ & 昙 & $\pi$ & & 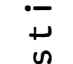 & - & $\stackrel{د}{.}$ & $\stackrel{\infty}{\infty}$ \\
\hline$\stackrel{10}{+}$ & $\stackrel{0}{\sim}$ & & $\underset{\pi}{\circ}$ & $\stackrel{1}{a}$ & $\begin{array}{l}0 \\
0 \\
0 \\
0\end{array}$ & & $\sigma$ & $\hat{\text { in }}$ & $\stackrel{\Delta}{>}$ & $\stackrel{100}{=}$ & ù & 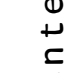 & $\begin{array}{l}n \\
0\end{array}$ & बे & o. & $\stackrel{\circ}{+}$ & & & & 0 & $\stackrel{0}{0}$ & $\underline{0}$ \\
\hline $\bar{\sigma}$ & 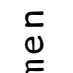 & $\begin{array}{l}n \\
0 \\
0\end{array}$ & $\underset{⿱}{\vec{D}}$ & $\underset{0}{n}$ & 1 & & $\begin{array}{l}1 \\
0 \\
0\end{array}$ & $\frac{0}{\pi}$ & 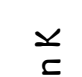 & $\stackrel{O}{\stackrel{O}{n}}$ & $\stackrel{0}{0}$ & $\frac{0}{1}$ & $m^{n}$ & $\stackrel{n}{n}$ & $\ddot{0}$ & $\underset{\sim}{5}$ & $\frac{\pi}{\pi}$ & & 离 & $\frac{E}{U}$ & $\stackrel{\pi}{=}$ & $\stackrel{\pi}{>}$ \\
\hline ú & $\frac{\pi}{0}$ & (iv) & $\begin{array}{l}0 \\
v\end{array}$ & $\stackrel{0}{L}$ & $m$ & & $n$ &. & $=$ & $\stackrel{\circlearrowright}{E}$ & $\vec{\jmath}$ & 4 & $\bar{E}$ & 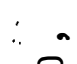 & $\approx$ & $\frac{1}{0}$ & $\stackrel{2}{2}$ & & & $\begin{array}{l}\sigma \\
Y\end{array}$ & $n$ & $\approx$ \\
\hline$\stackrel{0}{\stackrel{0}{0}}$ & $\stackrel{\mathbb{N}}{E}$ & $\begin{array}{l}0 \\
\stackrel{2}{0}\end{array}$ & $\frac{1}{\sigma}$ & $\stackrel{\pi}{a}$ & $\begin{array}{c}0 \\
\sim\end{array}$ & & $\stackrel{\circ}{\stackrel{0}{0}}$ & $\begin{array}{l}0 \\
5\end{array}$ & $\begin{array}{l}0 \\
0 \\
0 \\
10\end{array}$ & $\circ$ & $\stackrel{\circ}{+}$ & $\begin{array}{l}0 \\
\text { on }\end{array}$ & ${ }_{E}^{\dot{m}}$ & 0 & - & 0 & 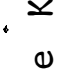 & & 0 & X & $\frac{0}{0}$ & ते \\
\hline 0 & ox & 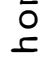 & ○ & $\frac{0}{0}$ & _- & & 荅 & $\begin{array}{l}4 \\
0 \\
1\end{array}$ & $\begin{array}{l}n \\
0 \\
0\end{array}$ & $i_{0}^{n}$ & 4 & $\sigma$ & u & $\stackrel{\sim}{n}$ & $\stackrel{\stackrel{一}{\sim}}{\therefore}$ & $\begin{array}{l}\Delta \\
\text { on }\end{array}$ & $\nabla$ & & $\overline{i \pi}$ & $n$ & $\stackrel{2}{\dot{2}}$ &.$n$ \\
\hline$\stackrel{\circ}{0}$ & $\frac{1}{a}$ & $\therefore$ & $i_{10}^{20}$ & $\stackrel{\pi}{0}$ & - & & & $\bar{a}$ & $\frac{1}{6}$ & 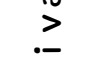 & 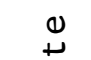 & $\frac{1}{\sigma}$ & $m$ & . & 10 & $\stackrel{x}{w}$ & $\stackrel{\circ}{1}$ & & $\bar{\sigma}$ & 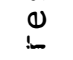 & ù & $\stackrel{\sim}{\sim}$ \\
\hline$\tilde{g}$ & 0 & $\stackrel{\mathbb{0}}{E}$ & $\therefore$ & 盯 & $\stackrel{\sigma}{-}$ & & $\stackrel{\circ}{\circ}$ & $\begin{array}{l}n \\
\pi\end{array}$ & $\stackrel{0}{1}$ & ${ }_{\sigma}^{+}$ & $\stackrel{n}{w}$ & a & " & $\stackrel{\circ}{m}$ & $\ddot{\infty}$ & & $\stackrel{\Gamma}{>}$ & & $\stackrel{0}{E}$ & $\frac{}{\pi}$ & ฮ & 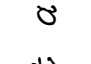 \\
\hline$\stackrel{1}{\circ}$ & ${ }_{0}$ & 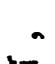 & 0 & To & 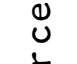 & & $\frac{\pi}{0}$ & $\stackrel{n}{\pi}$ & $\stackrel{n}{\pi}$ & $\therefore$ & & 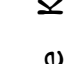 & $\begin{array}{l}\theta \\
\sigma\end{array}$ & in & $n$ & $\vec{i}$ & 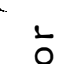 & & $\sigma$ & $\stackrel{0}{>}$ & $\stackrel{n}{0}$ & 0 \\
\hline$\stackrel{\pi}{>}$ & 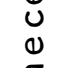 & $\frac{\pi}{0}$ & $a$ & $\circ$ & $\begin{array}{l}\pi \\
a\end{array}$ & & n & Oे & $\begin{array}{l}0 \\
0 \\
n\end{array}$ & $\bar{c}$ & 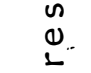 & 0 & $\frac{1}{\pi}$ & - & $\ddot{n}$ &. & $\underset{\Xi}{\complement}$ & & $\underset{\sim}{\pi}$ & $\stackrel{n}{0}$ & $\underset{c}{\Delta}$ & di \\
\hline$\stackrel{0}{0}$ & $\stackrel{\bar{\sigma}}{E}$ & $\therefore$ & $\infty$ & $\underset{\subseteq}{u}$ & $\underset{1 \pi}{\pi}$ & & $\stackrel{0}{0}$ & $\Xi$ & $\frac{0}{\frac{1}{\sigma}}$ & $\bar{n}$ & $\stackrel{\mathbb{\infty}}{\stackrel{\infty}{.}}$ & $\underset{1}{0}$ & $\circ$ & 0 & $\stackrel{+}{\underset{D}{0}}$ & $\dot{\bar{E}}$ & 0 & & c & $\stackrel{0}{\perp}$ & $\begin{array}{l}u \\
0\end{array}$ & 足 \\
\hline 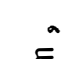 & $\overline{0}$ & & $\begin{array}{l}n \\
\sigma \\
\sigma\end{array}$ & 4 & $\infty$ & & 움 & & $\bar{\sigma}$ & $\omega_{\pi}^{\infty}$ & & $\frac{\pi}{\sigma}$ & O & 0 & $\underset{\sigma}{\tilde{E}}$ & - & 0 & $m$ & & ${ }_{0}^{c}$ & $n$ & 3 \\
\hline ป & a & : & जे & $\overline{\mathcal{O}}$ & $\stackrel{+}{\stackrel{c}{2}}$ & & ${ }_{\sigma}^{c}$ & & 完 & un & 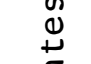 & $>$ & $\underset{x}{\bar{\nu}}$ & $\frac{\pi}{0}$ & $\therefore$ & m. & ' & $\bar{U}$ & $\frac{n}{\sigma}$ & $n$ & 욛 & 0 \\
\hline$\stackrel{\text { Ln }}{\sigma}$ & $\begin{array}{l}0 \\
0 \\
\pi\end{array}$ & $\sigma$ & $\because$ & 0 & 0 & & 2 & $\pi$ & $\stackrel{\infty}{\Phi}$ & $\overline{0}$ & $\stackrel{\overline{0}}{.}$ & ñ & 0 & $\overline{0}$ & $\stackrel{u}{u}$ & $\stackrel{\sim}{\underline{n}}$ & $\stackrel{-\pi}{=}$ & $\dot{m}=$ & שי & 苂 & $\bar{\pi}$ & $\stackrel{m}{a}$ \\
\hline$\frac{0}{0}$ & $\stackrel{\vec{c}}{\vec{c}}$ & $\begin{array}{l}0 \\
\infty \\
1\end{array}$ & $\begin{array}{l}n \\
\pi \\
\pi\end{array}$ & $\frac{\pi}{0}$ & $\begin{array}{l}4 \\
0\end{array}$ & & 倠 & $\stackrel{0}{0}$ & $\frac{\bar{c}}{u}$ & $\frac{4}{4}$ & $\frac{-1}{4}$ & $\stackrel{0}{2}$ & 믐 & $\begin{array}{l}5 \\
4\end{array}$ & $\begin{array}{l}0 \\
\text { in } \\
0\end{array}$ & $\ddot{\hat{a}}$ & 0 & $\bar{u}$ & i⿱ 20 & $\overline{0}$ & $\vec{\sigma}$ & \\
\hline$\stackrel{0}{0}$ & $\begin{array}{l}0 \\
0 \\
\sigma\end{array}$ & 웅 & & $\geq$ & n & & & $\stackrel{0}{-}$ & $\frac{-1}{4}$ & 0 & ชั & c &.$\underline{-}$ & $\frac{1}{0}$ & 1 & á & $\stackrel{0}{1}$ & m. & & 4 & & 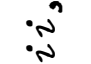 \\
\hline$\frac{\pi}{0}$ & $E$ & 先 & & $\stackrel{\vec{z}}{\vec{z}}$ & $\begin{array}{l}\infty \\
\pi \\
\pi\end{array}$ & & & $\begin{array}{c}0 \\
\infty\end{array}$ & نั & $\stackrel{\bar{\sigma}}{\sim}$ & $\stackrel{n}{0}$ & in & $n^{n}$ & n & $\begin{array}{l}0 \\
i \pi \\
0\end{array}$ & $\ddot{\sim}$ & 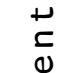 & 0 & & 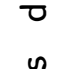 & $\stackrel{\text { D }}{\mathrm{c}}$ & $\widetilde{\sigma}$ \\
\hline 局 & م & L & & $\frac{5}{0}$ & $\frac{\pi}{\pi}$ & & & $\sigma$ & $\stackrel{n}{0}$ & $\begin{array}{l}\overline{0} \\
0\end{array}$ & $\stackrel{\sigma}{\square}$ & $\stackrel{c}{0}$ & & $\tau$ & $\approx$ & $\approx$ & $\sim$ & 0 & & $\frac{\pi}{0}$ & बे & $\vec{\theta}$ \\
\hline $\begin{array}{l}4 \\
0\end{array}$ & i⿱ & & & 0 & $\vec{\omega}$ & & & a & $\stackrel{0}{J}$ & $\frac{1}{a}$ & $\stackrel{0}{0}$ & ${ }_{4}^{1}$ & $\dot{0}$ & ס & & $\simeq$ & 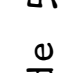 & $\frac{0}{0}$ & & $\frac{\pi}{0}$ & $\stackrel{0}{-}$ & 成 \\
\hline$\frac{1}{a}$ & $\bar{z}$ & $\bar{E}$ & & ర & & & & 记 & $\sigma$ & $\sigma$ & $\frac{8}{0}$ & & $\begin{array}{l}0 \\
\pi \\
0\end{array}$ & 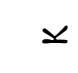 & $\stackrel{n}{m}$ & $\ddot{\tilde{n}}$ & & $\frac{\pi}{0} .-$ & & $\stackrel{\pi}{=}$ & $\bar{\sigma}$ & $\begin{array}{l}2 \\
\qquad \\
010\end{array}$ \\
\hline$\stackrel{0}{=}$ & $\bar{E}$ & $0^{\circ}$ & & $\stackrel{0}{1}$ & $\stackrel{0}{0}$ & $\stackrel{0}{+}$ & & _ & 0 & $\stackrel{i \pi}{\simeq}$ & $\stackrel{0}{u}$ & $\frac{0}{0}$ & $\bar{z}$ & $\frac{0}{0}$ & & $\therefore$ & i & 吉 & & $\stackrel{\sigma}{+}$ & $\stackrel{\circ}{\circ}$ & $\stackrel{-}{z}$ \\
\hline
\end{tabular}




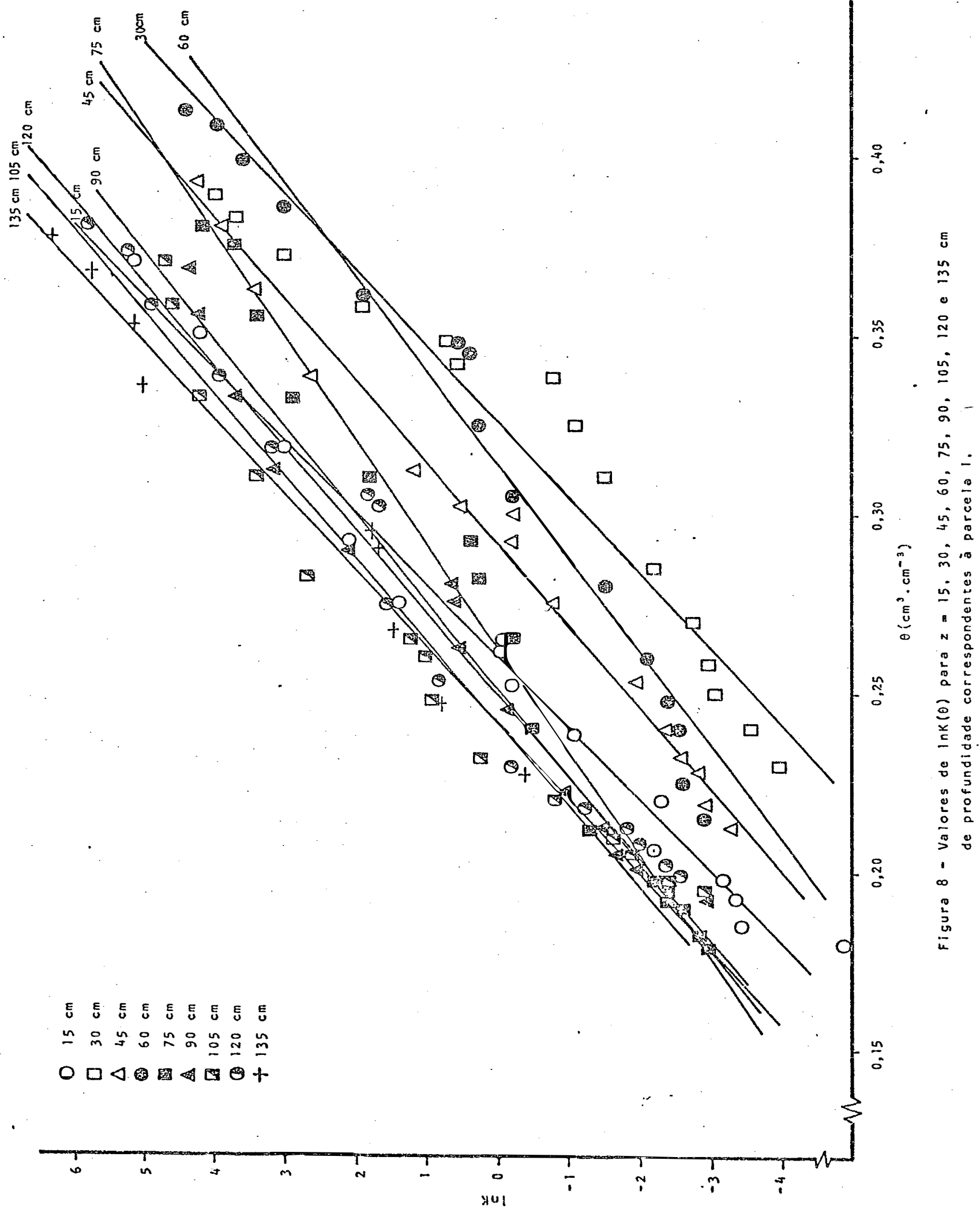




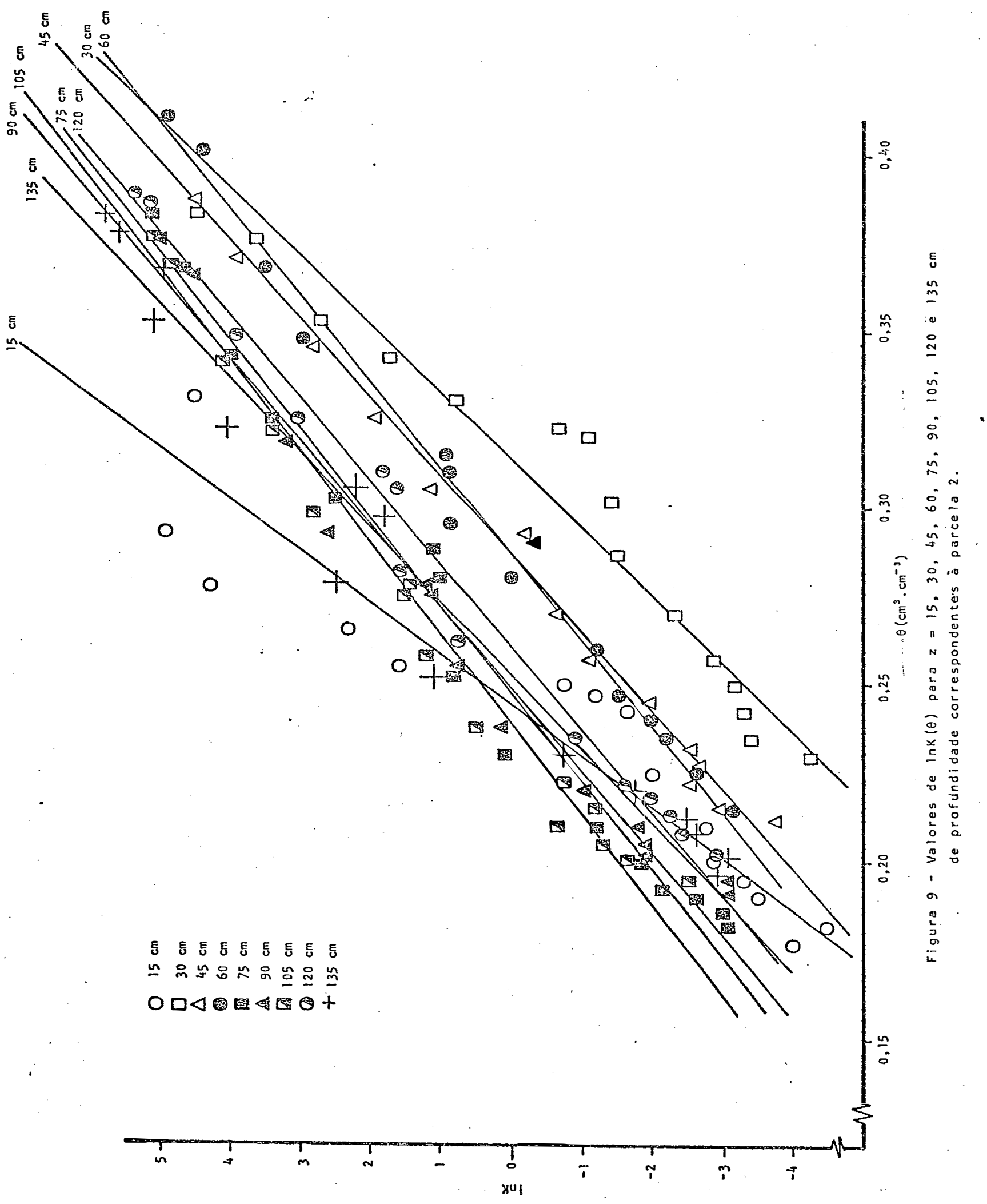




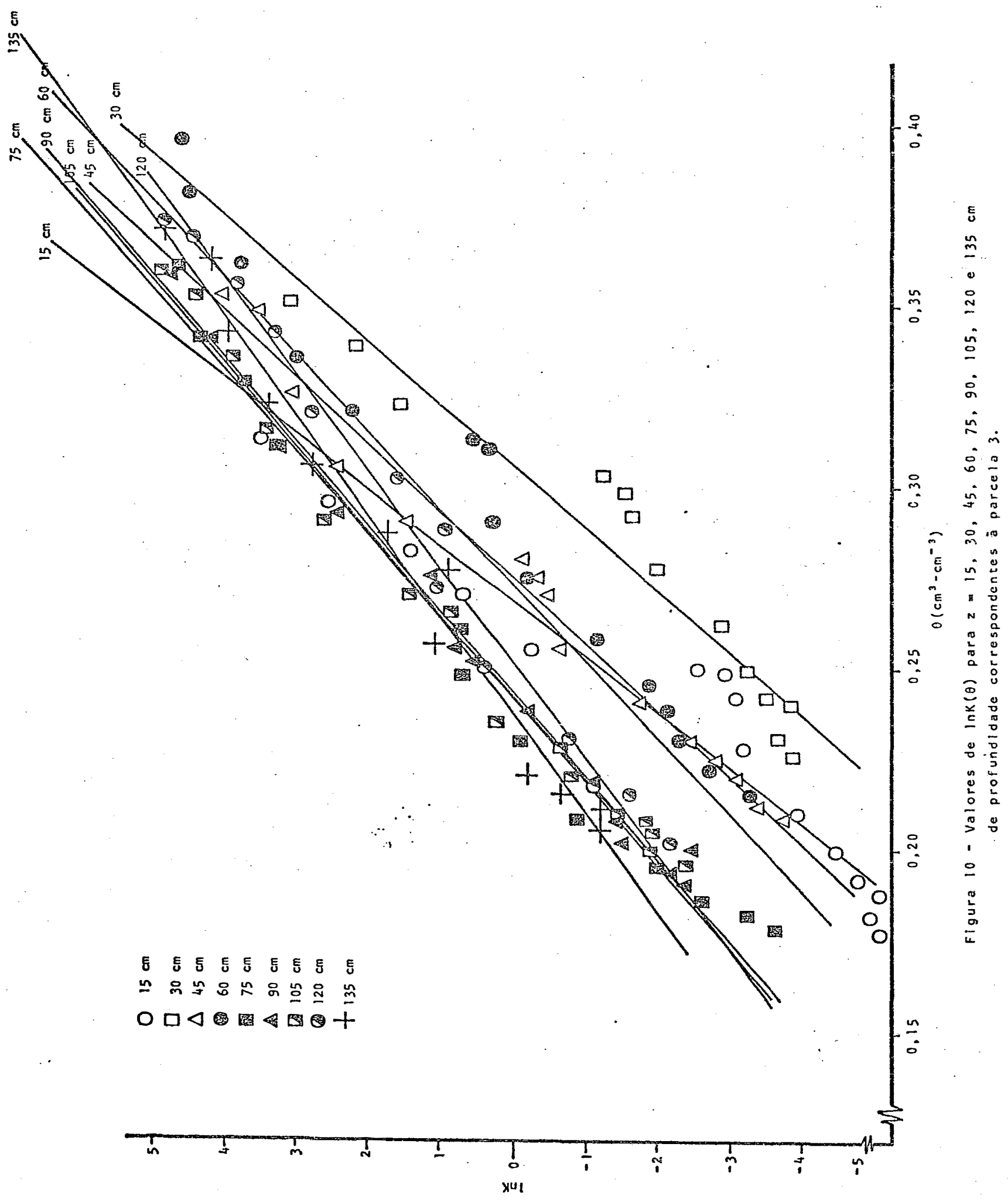




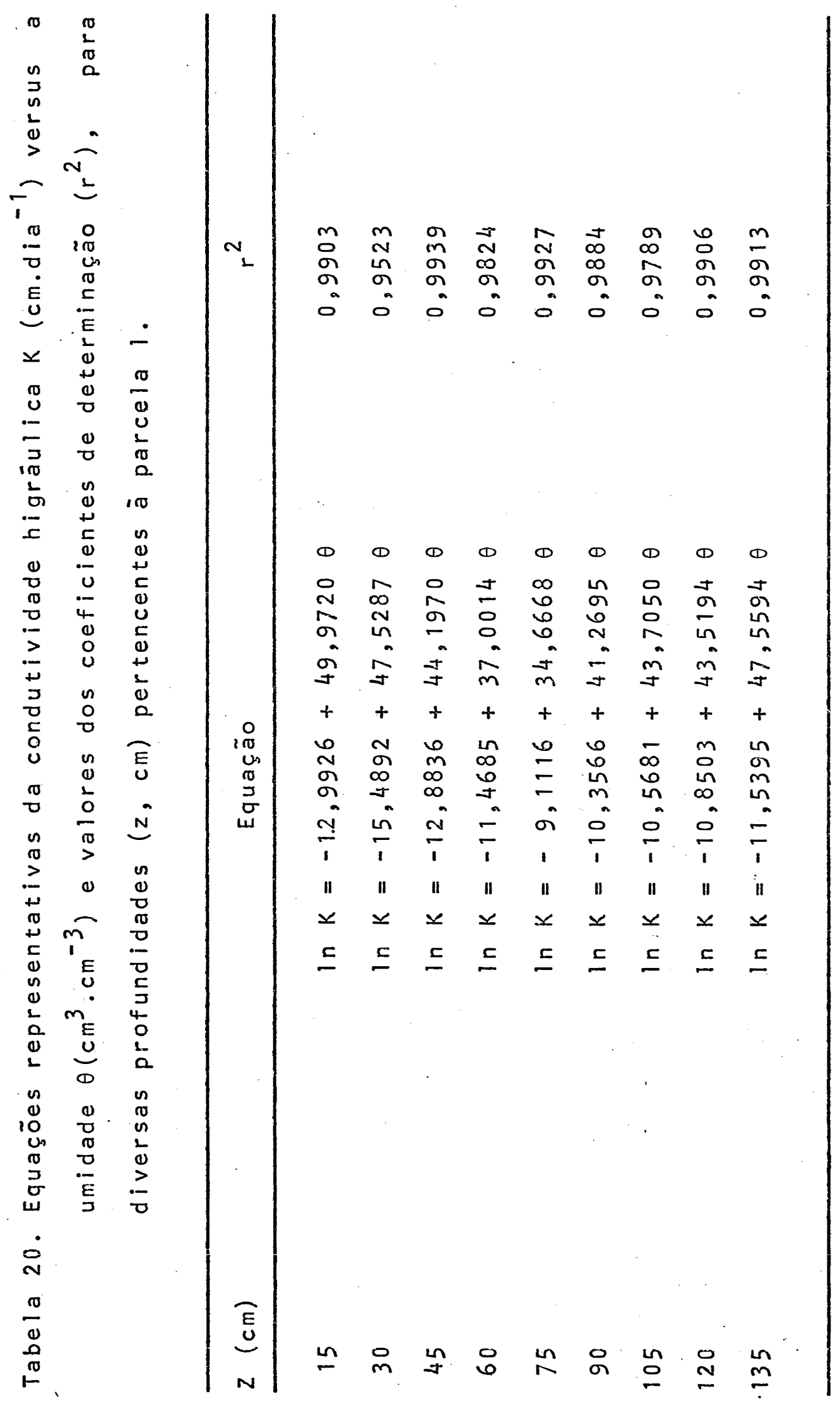


.60 .

lo, não seguem a distribuição normal.

Uma anālise semelhante poderia ser feita para os dados das parcelas 2 e 3 , apresentados nas Figuras 9 e 10 e Tabelas 21 e 22. Verifica-se portanto que, também para este solo, a variabilidade espacial no sentido da profundidade é de fundamental importancia, da mesma forma como observaram REICHARDT et alii (1976) para a Terra Roxa Estruturada.

A seguir apresentam-se as Figuras 11,12 e 13, que contêm os valores médios de $K(\theta)$ das três parcelas, para $z=15,30,45,60,75,90,105,120$ e $135 \mathrm{~cm}$. As barras nes tas figuras representam desvio padrão da média.

Nestas Figuras nota-se que a variabilidade é mais acentuada nas camadas superficiais, diminuindo sensivelmente para as camadas mais profundas.

A variabilidade espacial dos dados de condutividade hidráulica no sentido horizontal (entre parcelas) pode ser analisada comparando as equações de lnk versus $\theta$ para pro. fundidades fixas, que se encontram nas Tabelas 18,19 e 20 .

Assim por exemplo, para $\theta=0,30 \mathrm{~cm}^{3} \cdot \mathrm{cm}^{-3}$ obtêm- se os seguintes valores de $K$ para as diferentes profundidades, nas diferentes parcelas (Tabela 23). 


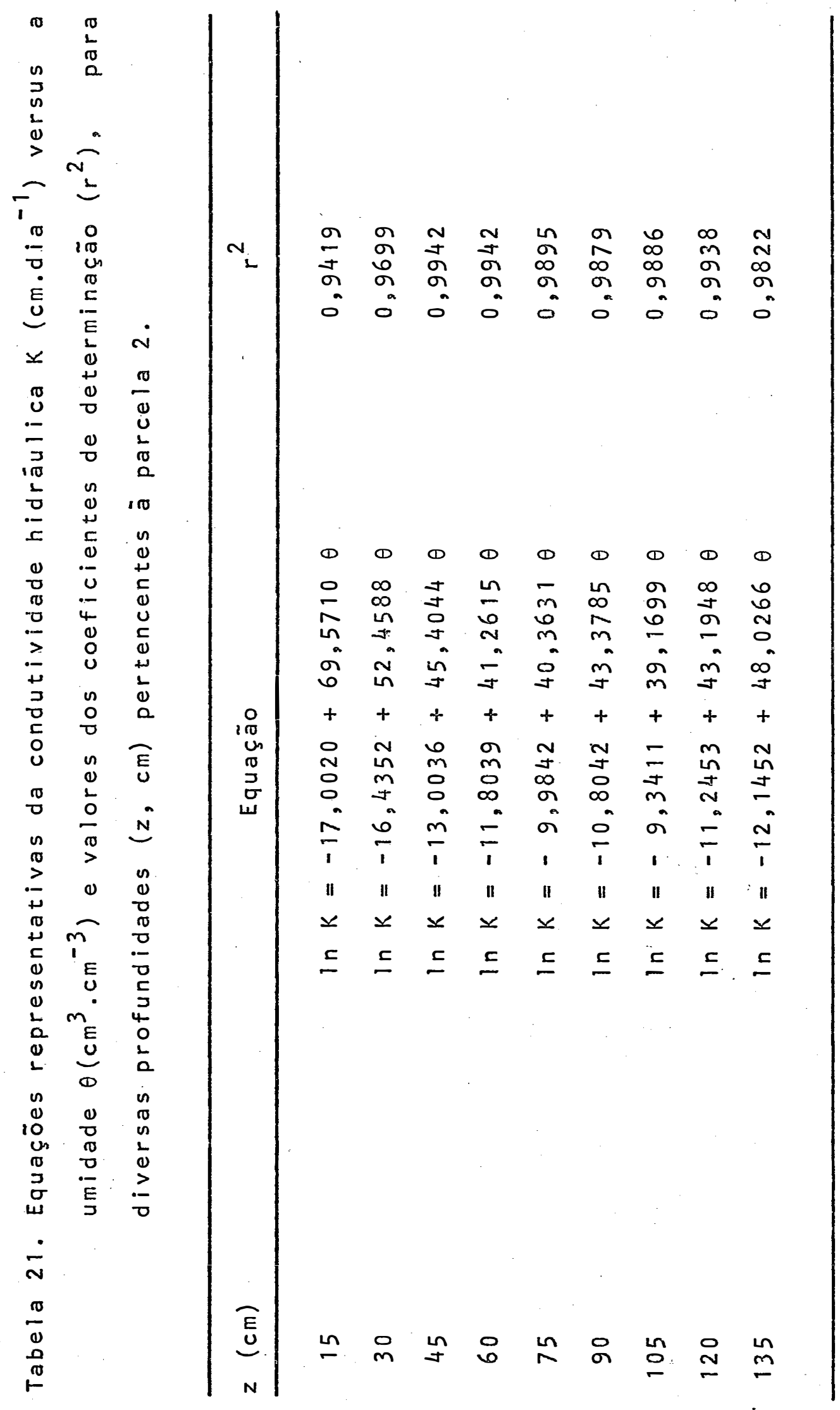

.61. 


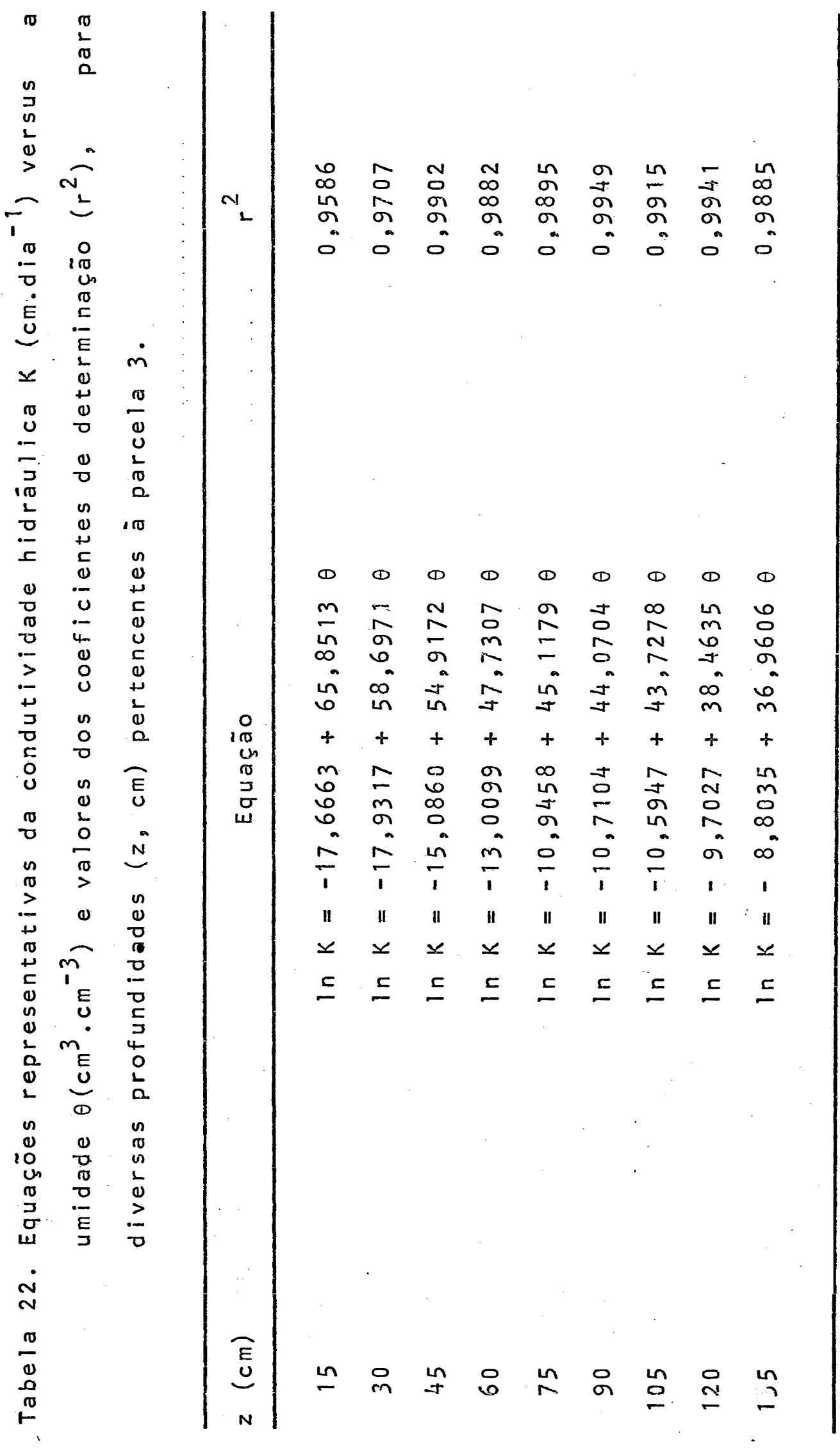


.63.

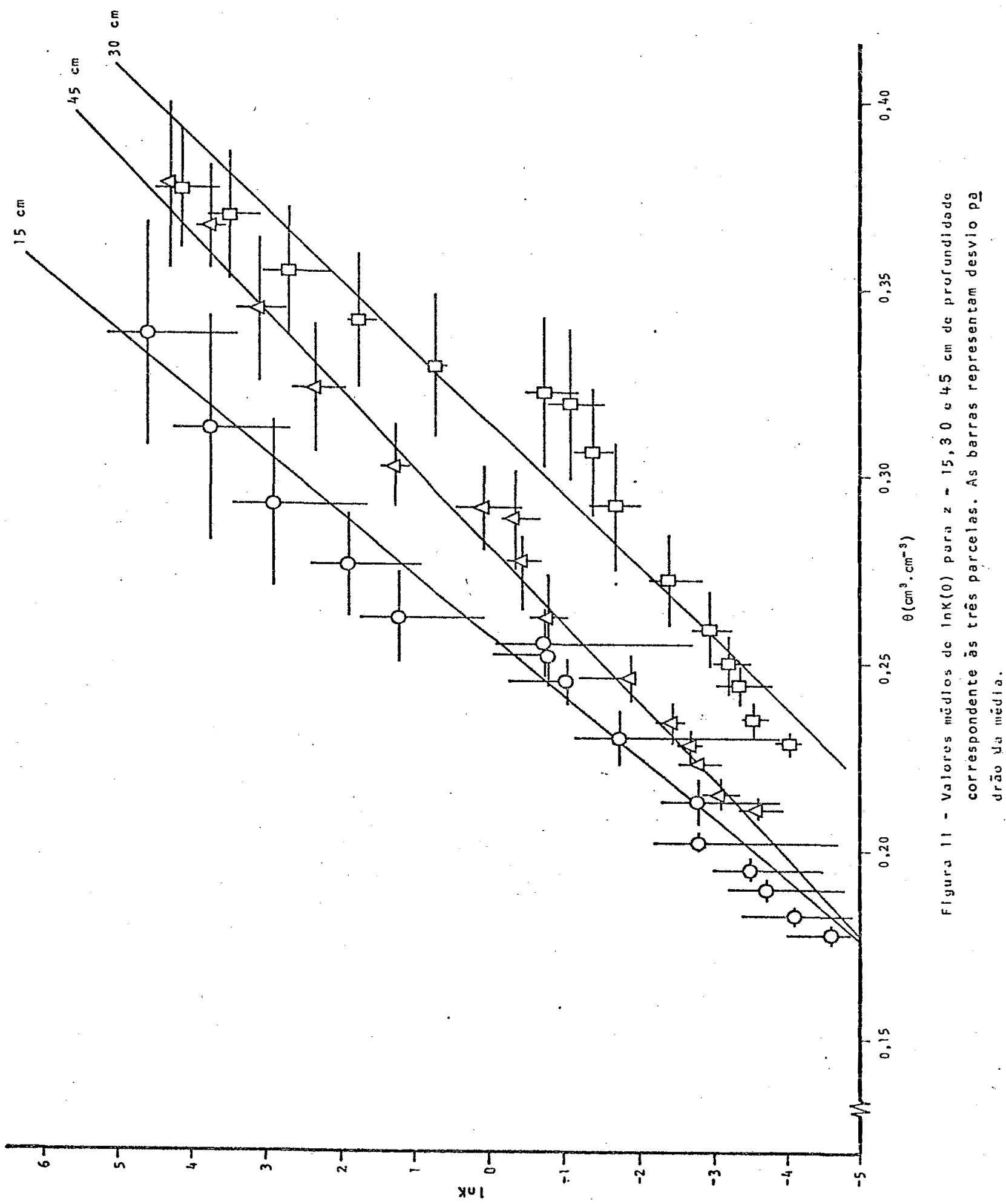


.64.

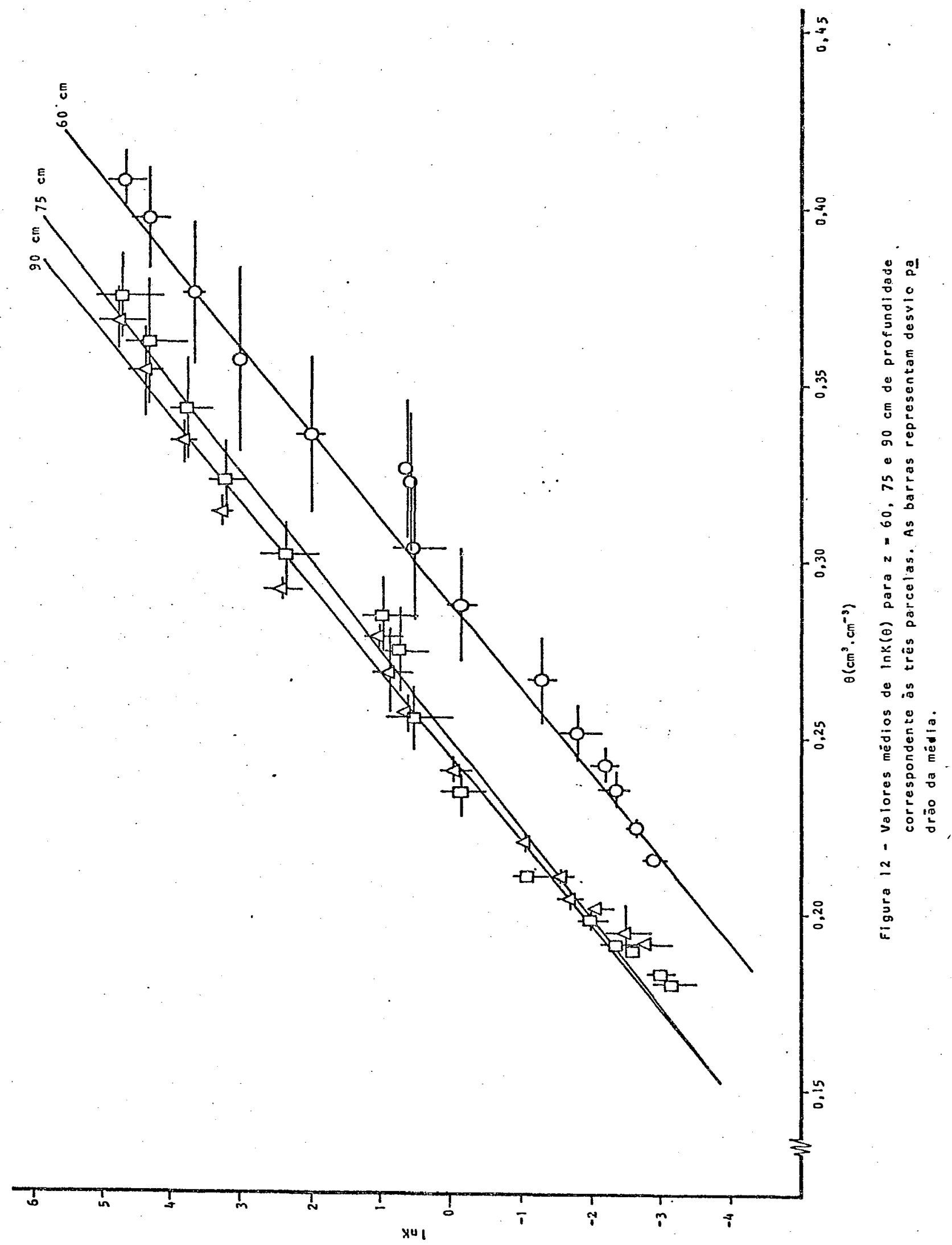




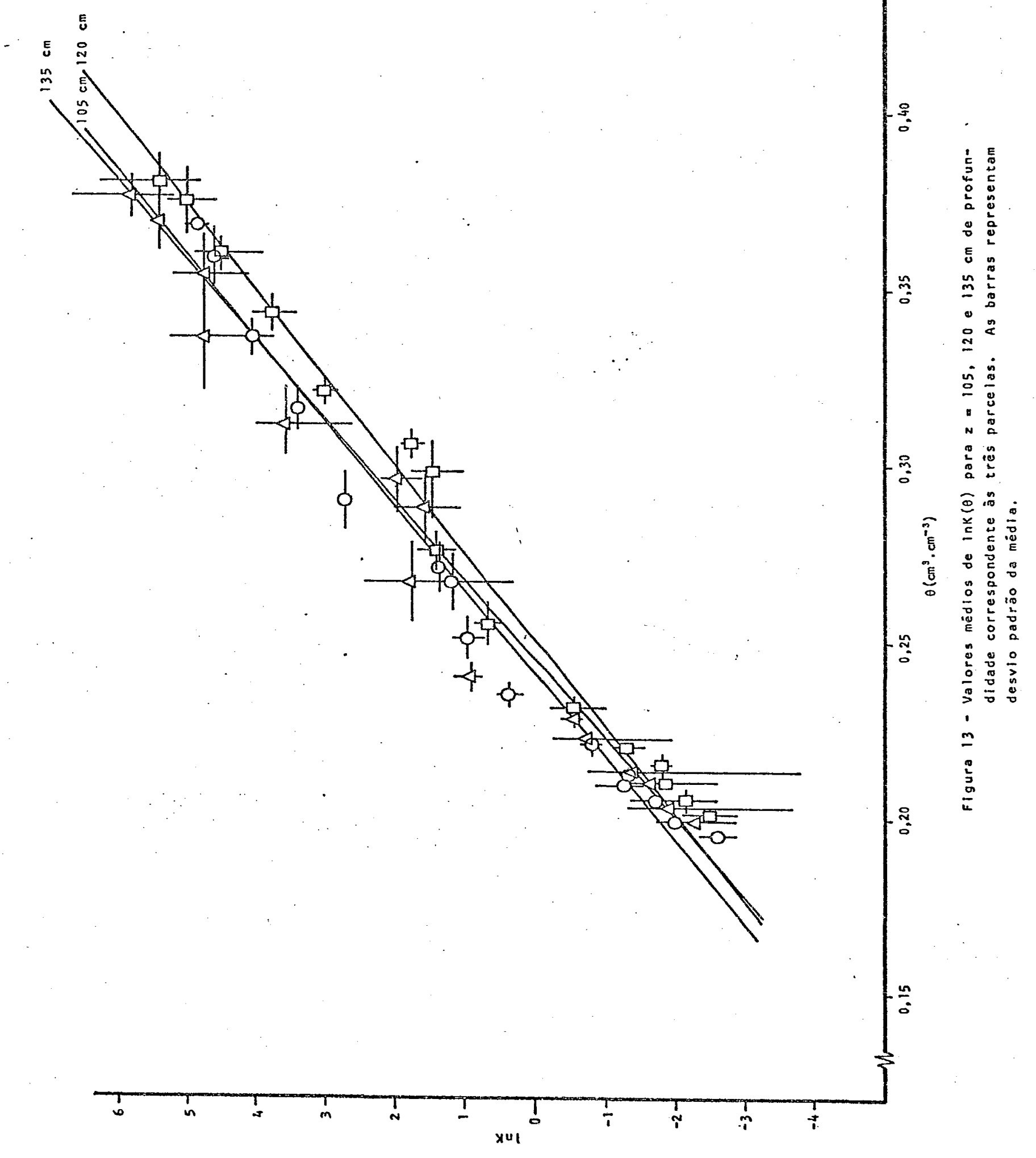


Tabela 23. Valores de condutividade hidräulica, para $\theta=0,30 \mathrm{~cm}^{3} \cdot \mathrm{cm}^{-3}$ para as diferentes profundidades nas três parcelas.

\begin{tabular}{|c|c|c|c|}
\hline \multirow{2}{*}{$\frac{\text { Profundidade }}{z}$} & \multicolumn{3}{|c|}{$P a r c e l a s$} \\
\hline & 1 & 2. & 3 \\
\hline 15 & 7,38 & 47,91 & 8,08 \\
\hline 30 & 0,29 & 0,49 & 0,72 \\
\hline 45 & 1,46 & 1,85 & 4,01 \\
\hline 60 & 0,69 & 1,78 & 3,70 \\
\hline 75 & 3,63 & 8,37 & 13,32 \\
\hline 90 & 7,57 & 9,11 & 12,31 \\
\hline 105 & 12,72 & 11,13 & 12,47 \\
\hline 120 & 9,07 & 5,55 & 6,27 \\
\hline 135 & 15,31 & 9,61 & 9,82 \\
\hline
\end{tabular}


Como se pode verificar a variabilidade no sentido horizontal pode ser pronunciada, até mesmo para profundi dades maiores. 0 uso de valores médios pode portanto trazer erros consideráveis na estimativa de fluxos de água neste so1o. Este fato já foi evidenciado em nosso meio por REICHARDT et alii (1977) para o solo Terra Roxa Estruturada, porēm de forma mais pronunciada que para o caso do solo do presente es tudo. A obtenção de valores médios representativos é assunto recente da física de Solos (BIGGAR et alii, 1976, SIMONS et alii, 1978 e WARRICK et alii, 1977) e para isto é necessārio um grande nümero de dados que permita a determinação de sua distribuição real, para que métodos estatísticos adequados se jam utilizados.

Acreditamos porēm que os dados obtidos para as profundidades maiores $(z>75 . \mathrm{cm})$ possam ser utilizados com relativa segurança na estimativa de fluxos de àgua no solo pạ ra efeito de estabelecimento de balanço hídrico. Nestas cama das mais profundas o solo torna-se mais homogêneo, a variabilidade espacial menos pronunciada, de tal forma que valores médios e desvios padrões obtidos segundo uma distribuição nor mal provavelmente sejam viāveis. 
6. CONCLUSOES

Da discussão dos resultados obtidos neste trabalho conclui-se que:

1. Do ponto de vista da caracterização física, no que se refere a propriedades estäticas,o .solo é praticamente homogêneo até a profundidade de $135 \mathrm{~cm}$.

2. A condutividade hidráulica saturada obtida para as 3 parcelas, durante o processo de infiltração, apresentou uma média de 6,57 cm.hora-1, com um coeficiente de variação de $29 \%$.

3. A determinação da condutividade hidráulica pelo método do perfil instantâneo utilizando apenas tensiômetros e curvas de retenção, elaboradas com amostras de solo com es 
trutura indeformada, ē bastante válida para este solo.

4. A variabilidade espacial em profundidade da condutividade hidráulica do solo é acentuada, visto que para um mesmo teor de umidade o desvio entre o menor e o maior valor obti do foi da ordem de $100 \%$.

5. 0s dados de condutividade hidräulica na direção horizontal também apresentam variabilidade pronunciada.

6. De modo geral, a variabilidade deste coeficiente de transmissão de água para este solo é maior nas camadas superficiais diminuindo sensivelmente nas camadas mais profundas, podendo-se dizer que, para profund dades maiores que $75 \mathrm{~cm}$, valores médios podem ser utilizados com relativa segurança na estimativa de drenagem profunda para efeito de estabelecimento de balanços hidricos. 


\section{SUMMARY}

This work consists of the physical and hydric characterization of an 0xisol (Haplustox) that was made on three experimental plots of $5 \times 5 \mathrm{~m}$, located on the campus of Escola Superior de Agricultura "Luiz de Queiroz", University of São Paulo. The relation between soil hydraulic conductivity and soil water content $K(\theta)$ was established through the instantaneous profile method, according to the procedure suggested by HILLEL et ali $i .(1972$ ) and the modification introduced by CHO et alii (1977).

The spatial variability of hydraulic conductivity was analysed horizontally and in depth, within the three experimental plots.

Total soil water potential was measured through tensiometers installed in the three experimental plots at the depths of $15,30,45,60,75,90,105,120$ and $135 \mathrm{~cm}$. Soil water content values were infered from tensiometer readings 
using soil water retention curves constructed with indisturbed soil cores from all depths. These samples were collected in two pits near to the experimerital plots, with six replications.

It was observed that the spatial variability of soil hydraulic conductivity was more pronounced at surface layers, being less important at greater depths. It was concluded that for depths greater than $75 \mathrm{~cm}$, average values of soil hydraulic conductivity could be used with relative confidence in the estimation of soil water fluxes in water balance studies. 


\section{LITERATURA CITADA}

ALEMI, M.H., D.R. NIELSEN e J.W. BIGGAR. 1976. Determining the hydraulic conductivity of soil cores by centrifugation. Soil Sci. Soc. Am. J. Madison 40:212-218.

BAKER, F.G., P.L.M. VENEMAN e J. BOUMA. 1974. Limitation of the instantaneous profile method for field measurement of unsaturated hydraulic conductivity. "Soiz Sci. Soc. Amer. Proc., 38:885-888.

BIGGAR, J.W. and D.R. NIELSEN. 1976. Spatial variability of the leaching characteristics of a field soil. Water Resources Research, 12:78-84.

BRUCE, R.R. e A. KLUTE. 1956. Measurement of soil moisture diffusivity. Soiz Sci. Soc. Amer. Proc. Madison, 20:458-462. 
BUCKINGHAM, E. 1907. Studies on the movement of soil moisture. Bul. Bur. Soizs U.S. Dept. Agr., 38.

CAVALCANTE, L.F.; K. REICHARDT e P.L. LIBARDI. 1978. Determinação da condutividade hidrāulica do solo durante a redistribuição da àgua. Campinas (SP), R. Bras. Ci. Solo (no pre10).

CHILDS, E.C. e N. COLLIS-GEORGE. 1950. The permeability of porous materials. Roy. Soc. Proc. Londres, A.201:392-405.

CHO, T., Y. NOMURA, T. YANO, S. SHIKASHO e M. INOUE. 1976. The use of neutron moisture mețer in studies of soil water regimes. Water management in a sand dune ärea, Tottori University, Faculty of Agriculture. 48p. A report for the coordinated research programme on the use of radiation and isotope techniques in studies of soil water regime. IAEA.

CHO, T., Y. NOMURA; T. YANO S S. SHIKASHO e M. INOUE. 1977. The Use Surface-Type and a Depth-Type Neutron Moisture Meter in Studies of Soil Water Regimes - Water Management in a Sand Dune Area. A report for the coordinated research programme on the use of radiation and isotope techniques in studies of soil-water regimes. IAEA. Tottori University. $85 p$. 
CLIFFOED, A.A. 1973. Multivariate Error Analysis. Appl. Sci. Publ. London. $112 \mathrm{p}$.

DARCY, H. 1856. Les Fontaines Publiques de la Ville de Dijon. Paris, Victor Dalmont. $592 \mathrm{p}$.

FLÜHLER, H.; M.S. ANDAKANI e L.H. STOLZY. 1976. Error propagation in determining hidraulic conductivities from sucessive water content and pressure head profile. Soil Sci. Amer. Journ., 40:830-836.

GROHMANN, F.; O. BRUNINI e K. REICHARDT. 1976. Condutividade hidráulica do solo. Campinas, Instituto Agronômico.Cir cular n? 53. $28 p$.

HILLEL, D., V.D. KRENTOS e Y. STYLIANOU. 1972. Procedure and test of an internal method for measuring soil hydraulic characteristics in situ. Soil Sci. Baltimore, 114:395-400.

KLUTE, A. 1973. Soil water flow theory and its application in field situations. In: $B R U C E, R . R$. ed., field soil water regime. Madison, Soil Sci. Soc. Amer. Cap. 2, p. $9-35$.

LIBARDI, P.L. 1974. Infiltração da āgua no solo: Uma genera lização. Piracicaba (SP), ESALQ/USP. 46p. (Tesee de Mestrado) 
MARINI, P., P. VILLEMIN e O. JOURDAN. 1977. Definition des Proprietes Hydrodinamiques des Sols du Perimetre Sucrier D'Avalaiva. Contrat de Recherche avec L'Agence Internationale de L'Energie Atomique. Université de Madagascar. $41 p$.

MARSHALL, T.J. 1958. A relation between permeability and . size distribution of pores. J. Soil Sci. Londres, $9: 1-8$.

MILLINGTON, R.J. e J.P. QUIRK. 1959. Permeability of porous media. Nature, 183:387-388.

MILLINGTON, R.J. e J.P. QUIRK. 1960. Transport in porous media. Trans. of 7 th Int. Congr. Soil Sci. Madison, $1: 97-106$.

MILLINGTON, R.J. e J.P. QUIRK. 1961. Permeability of porous solids. Trans. Faraday Soc., 57:1200-1207.

NIELSEN, D.R., D. KIRKHAM e E.R. PERRIER. 1960. Soil

capillary conductivity: comparison of measured and calculated values. Soil Sci. Soc. Amer. Proc. Madison, 24:157-160. 
NIELSEN, D.R., J.M. DAVIDSON, J.W. BIGGAR e R.J. MILLER. 1962. Water movement through panoche clay loam soil. Hilgardia Berkeley, 35:491-506.

NIELSEN, D.R., J.W. BIGGAR e K.T. ERH. 1973. Spatial variability of field-measured soil-water properties. Hizgardia, 42:215-259.

OGATA, G. e L.S. RICHARDS. 1957. Water content changes following irrigation of bare field soil that is protected from evaporation. Soil Sci. Soc. Amer. Proc. Madison, $21: 355-356$.

REICHARDT, K., D.R. NIELSEN e J.W. BIGGAR. 1972. Scaling of horizontal infiltration into homogeneous soil. Soil Sci. Soc. Amer. Proc. Madison, 36:241-245.

REICHARDT, K. e P.L. LIBARDI. 1974. An Analysis of SoilWater Movement in the Field: I. Hidrological Field site Characterization. Piracicaba, SP. 21P. BC-021, CENA. REICHARDT, K., P.L. LIBARDI e D.R. NIELSEN.. 1975. Unsatured hidraulic conductivity determination by a scaling Technique. Soir Sci. Soc. Amer., 120:165-168. 
REICHARDT, K., F. GROHMANN, P.L. LIBARDI e S.V. QUEIROZ. 1976. Spatial variability of physical properties of a tropical soil: 11. Soil water retention curves and hydraulic conductivity. Piracicaba, SP. 24p. BT-005, CENA.

REICHARDT, K., P.L. LIBARDI, L.C.U. SAUNDERS e E. FREITAS Jr. 1977. Dificuldades do uso da equação de Darcy para descrever o movimento de àgua em solo não saturado no campo. Anais do V Encontro Escoamento em Meios Porosos. V. $114 / 1-$ $-4 / 9$, COPPE/UFRJ.

RICHARDS, L.A. 1931. Capillary conduction of liquid through porous media. Physics, 1:318-333.

RICHARDS, S.J. e L.V. WEEKS. 1953. Capillary conductivity values from moisture, yield and tension measurements on soil columns. Soil Sci. Soc. Amer. Proc., 17:206-209.

RICHARDS, L.A., W.R. GARDNER e G. OGATA. 1956. Physical processes determining water loss from soil. Soil Sci. Soc. Amer. Proc. Madison, 20:310-314.

ROSE, C.W., W.R. STERN E J.E. DRUMOND. 1965. Determination of hydraulic conductivity as a function of Depth and water content for soil in situ. Aust. Journ. Res., 3:1-9. 
SAUNDERS, L.C.U., P.L. LIBARDI e K. REICHARDT. 1978. Condutividade hidräulica da terra roxa estruturada em condições de campo. Campinas, R. bras. Ci. Solo (no prelo).

SIMMONS, C.S., D.R. NIELSEN e J.W. BIGGAR. 1978. Scaling of field-measured soil water properties. Hilgardia (submitted).

SLICHTER, C.S. 1898. Theoretical investigation of the motion of ground water. U.S. Geol. Survey 19 th Annual Report, part 2, p.295-384.

SWARZENDRUBER, D. 1969. The flow of water in unsaturated soils. In: DE WEST, R.J.M. ed., flow through porous media. New York Academic Press, Inc., Cap.6, p.215-292.

VACHAUD, G. 1967. Determination of the hydraulic conductivity of unsaturated soils from an analysis of transient flow data. Water Res. Washington, 3:697-705.

VACHAUD, G., C. DANCETTE, S. SONKO e J.L. THONY. 1977. Methodes de caracterization hydrodynamique in situ d'um sol non sature. Grenoble, Institut de Mecanique de Grenoble, IMG-CNRS. $28 \mathrm{p}$.

WARRICK, A.W., G.J. MJLLEN and D.R. NIELSEN. 1977. Scaling field-measured soil hydraulic properties using similar media concept. Water Resources Research, 13:355-362. 